\title{
Desdobramento da função qualidade aplicado ao projeto de um detergente sustentável
}

\author{
Ângela Maria Marx ${ }^{a *}$, Marcia Elisa Soares Echeveste ${ }^{b}$, \\ Istefani Carísio de Paula ${ }^{\mathrm{c}}$ \\ a*amarx@producao.ufrgs.br, UFRGS, Brasil \\ becheveste@producao.ufrgs.br, UFRGS, Brasil \\ cistefani@producao.ufrgs.br, UFRGS, Brasil
}

\begin{abstract}
Resumo
Este trabalho tem como objetivo apresentar um modelo descritivo de QFD que incorpora critérios de sustentabilidade, bem como sua aplicação no desenvolvimento de um detergente sustentável. A inclusão desses critérios é realizada por meio da avaliação da importância relativa dos componentes (partes) do detergente, o que possibilita a sua redução, e pela incorporação de uma matriz para a avaliação da sustentabilidade das matérias-primas. A aplicação do modelo permite priorizar os componentes, indicando quais poderiam ser eliminados da fórmula com o mínimo impacto nas demandas do produto final. Em seguida, as matérias-primas disponíveis são avaliadas em relação a critérios de sustentabilidade e priorizadas de acordo com sua importância relativa para o produto final. Os resultados do estudo indicam que a utilização do modelo proposto é adequada para aplicações industriais, contribuindo para o desenvolvimento de produtos mais sustentáveis orientados pelas demandas do mercado.
\end{abstract}

Palavras-chave

QFD. Projeto. Produto. Sustentabilidade.

\section{Introdução}

Nos primeiros tempos da consciência ambiental nas indústrias, o foco de atuação esteve concentrado nas soluções end-of-pipe, baseadas na redução de emissões nas unidades industriais. Recentemente, esta visão foi substituída por um foco na performance ambiental dos produtos, refletindo a mudança para um enfoque preventivo (JOHANSSON, 2002).

De acordo com Rozenfeld et al. (2006), o Processo de Desenvolvimento de Produtos (PDP) inicia-se no entendimento das necessidades de mercado, passa pela criação de valor e termina no final do ciclo de vida do produto. Os autores ressaltam, ainda, que a antiga fórmula de sucesso baseada em criar um produto, produzi-lo a baixo custo e vendê-lo em grande quantidade não é mais aplicável no atual ambiente de negócios. Agora, os produtos precisam ser desenvolvidos para atender a demandas e segmentos específicos de mercado, incorporando novas tecnologias e funcionalidades e adequando-se a padrões ou a restrições legais.
A necessidade de desenvolver produtos e tecnologias limpas resultou no emprego de diversas técnicas para otimizar os sistemas de produção, bem como na criação de ferramentas voltadas para a sustentabilidade. No entanto, essa implementação ainda é um desafio para a indústria de bens de consumo (PUJARI; WRIGHT, 1999). Atualmente, a maioria dos esforços para desenvolver produtos sustentáveis ainda está focada em apenas dois dos três aspectos da sustentabilidade: ecologia e economia (DIEHL; BREZET, 2004), constituindo uma abordagem denominada ecodesign. Labuschagne, Brent e Erck (2005) corroboram essa ideia, afirmando que a maioria dos métodos para avaliação da sustentabilidade de produtos aborda principalmente a dimensão ambiental, em detrimento das dimensões econômica e social. Os autores enfatizam que existem poucos métodos que considerem as três dimensões da sustentabilidade e que apresentem indicadores ambientais, sociais e econômicos. Em virtude disso, ainda existe uma 
demanda intensa por métodos para a avaliação da sustentabilidade (UGWU; HAUPT, 2007).

Baumann, Boons e Bragd (2002) afirmam que a maioria das pesquisas voltadas para a sustentabilidade dos produtos apenas descreve ferramentas de forma conceitual. De acordo com os autores, são poucos os estudos que apresentam como essas ferramentas se encaixam no Processo de Desenvolvimento de Produtos (PDP), isto é, de que forma e em qual fase devem ser usadas. Além disso, a maioria desses estudos apresenta ferramentas para as fases de detalhamento do produto, havendo oportunidades para o desenvolvimento de ferramentas que atuem nas fases iniciais do PDP (BHAMRA et al., 1999), uma vez que essas fases são críticas para o desenvolvimento de produtos sustentáveis (KARA; HONKE; KAEBERNICK, 2005).

Considerando a existência dessa lacuna, este trabalho está focado nas fases iniciais do PDP, até o conceito do produto. 0 objetivo deste trabalho é propor um modelo descritivo que utiliza a ferramenta de planejamento Desdobramento da Função Qualidade (QFD), à qual foi integrada a Matriz do Índice $S$ (MARX; PAULA, 2008), empregada para auxiliar a avaliação do impacto da sustentabilidade de matérias-primas. 0 intuito é apresentar um método prático para introduzir critérios de sustentabilidade no desenvolvimento de produtos, adequado para aplicações industriais.

Este artigo apresenta-se estruturado da seguinte forma: referencial teórico, descrição do método de pesquisa e do modelo descritivo proposto, aplicação do modelo ao estudo de caso de um detergente sustentável, discussão dos resultados e conclusões.

\section{Referencial teórico}

0 referencial teórico deste artigo está dividido em três seções. Na primeira, é feita uma revisão a respeito das abordagens para o desenvolvimento de produtos sustentáveis. A segunda seção consiste em um breve referencial sobre QFD. Por fim, a terceira seção apresenta a Matriz do Índice $S$, inserida no modelo descritivo proposto de QFD.

\subsection{Desenvolvimento de produtos sustentáveis}

A necessidade de desenvolver produtos sustentáveis em função de pressões legais e de mercado levou diversas empresas a adotarem a sustentabilidade como uma estratégia competitiva que traz benefícios econômicos e promove a melhoria da imagem corporativa (KARA; HONKE; KAEBERNICK, 2005).

De acordo com Abele, Anderl e Birkhofer (2005), as questões ambientais sempre estiveram presentes indiretamente no PDP convencional, cujo foco está concentrado em qualidade, custo e tempo. Embora tenham ocorrido avanços significativos na adoção de ferramentas e métodos, ainda não foi criada uma metodologia específica para o desenvolvimento de produtos sustentáveis (ABELE; ANDERL; BIRKHOFER, 2005). A literatura a respeito de ecodesign sugere a integração dos aspectos ambientais ao PDP convencional, não considerando a necessidade de uma metodologia diferenciada (FIKSEL, 1993; BHAMRA et al., 1999; ABELE; ANDERL; BIRKHOFER, 2005; MANZIN1; VEZZOLl, 2005).

0 ecodesign, também chamado de Projeto para o Meio Ambiente, do inglês Design for Environment (DfE), tem como objetivo minimizar o impacto ambiental de todo o ciclo de vida do produto, considerando as questões ambientais desde o início do desenvolvimento de um novo produto (DIEHL; BREZET, 2004). Entre as principais estratégias ou diretrizes do ecodesign estão: 1) a desmaterialização do produto; 2) a otimização funcional do produto; 3) a seleção de materiais de baixo impacto; 4) a redução do número de partes e materiais; 5) a otimização de técnicas de produção e transporte; 6) a redução de impacto no uso do produto; e 7) o aumento do tempo de vida útil do produto (BREZET; HEMEL, 1997).

Conforme exposto anteriormente, existem muitas ferramentas disponíveis para a aplicação dos princípios de ecodesign no PDP, embora poucas considerem todas as três dimensões da sustentabilidade (LABUSCHAGNE; BRENT; ERCK, 2005). Além disso, essas ferramentas estão mais voltadas para a fase de desenvolvimento físico do produto (BHAMRA et al., 1999). Isso é compreensivel, uma vez que a abordagem inicial da sustentabilidade está voltada para o eco-redesign dos produtos. Com a evolução das abordagens de sustentabilidade para enfoques estratégicos e mais abrangentes, a questão é trazida para as fases iniciais do PDP, que passam a ter um volume maior de informação, especialmente em relação a uma série de requisitos que não eram levados em consideração nos projetos tradicionais.

De acordo com Bhamra et al. (1999), algumas empresas já perceberam a importância de incluir as questões de sustentabilidade nas fases iniciais do PDP e estão procurando formas de promover essa implementação. Nessas fases, a equipe de projeto explora as possibilidades de produto e combina as necessidades dos clientes, os requisitos de sustentabilidade, os objetivos corporativos, as ideias de produtos e as tecnologias existentes para chegar ao conceito do produto. As fases relacionadas com essas atividades são denominadas Projeto Informacional e Projeto Conceitual, enquanto a fase de detalhamento do produto é conhecida como Projeto Detalhado (ROZENFELD et al., 2006). 
Em linhas gerais, o Projeto Informacional tem como objetivo organizar uma lista de objetivos e especificações de projeto mensuráveis, partindo da ideia estabelecida durante o planejamento estratégico do produto e fazendo uso de uma série de requisitos subjetivos obtidos a partir dos consumidores (FERREIRA et al., 2006). De acordo com Pahl et al. (2005), o Projeto Conceitual é a parte do PDP em que é definida a solução preliminar a ser utilizada, por meio da identificação dos principais problemas e pelo estabelecimento das estruturas funcionais e suas combinações. 0 Projeto Detalhado, por sua vez, é a fase em que o conceito preliminar é transformado nas especificações finais do produto, e são detalhados os subsistemas, os processos de fabricação e os recursos necessários, bem como o plano de fim de vida do produto (ROZENFELD et al., 2006).

A existência de um PDP estruturado e o uso de ferramentas adequadas são importantes para 0 desenvolvimento de produtos sustentáveis, mas não garantem, por si só, o sucesso desses produtos. Pujari e Wright (1999) argumentam que o caminho para uma integração efetiva das questões ambientais no desenvolvimento de produtos está em uma relação estreita com os fornecedores e na adoção de um forte foco no cliente. Os autores explicam que a rede de suprimentos apresenta-se como uma importante fonte de informações e parceria, possibilitando o desenvolvimento de alternativas em relação a materiais, componentes e processos. Uma vez que o foco no cliente é fundamental para que o consumidor tenha preferência pelo produto sustentável ao invés dos produtos convencionais, esta é uma condição importante para que o produto traga os benefícios esperados em termos de sustentabilidade (PUJARI; WRIGHT, 1999).

\subsection{Desdobramento da função qualidade}

0 Desdobramento da Função Qualidade, do inglês Quality Function Deployment (QFD), é um método utilizado para o desenvolvimento e a melhoria de produtos e serviços. 0 QFD foi concebido por Yoji Akao e Katsuyoshi lshihara para garantir a qualidade no desenvolvimento de produtos por meio de uma abordagem orientada pelo consumidor (MIZUNO; AKAO, 1994). Originalmente, o método é composto por 27 etapas, enfatizando qualidade, tecnologia, custos e confiabilidade. Os principais benefícios de sua utilização são o aumento na qualidade de produtos, a diminuição de reclamações de consumidores e a redução no custo e no tempo de desenvolvimento de produtos e serviços (CHENG; MELO FILHO, 2007).

Diversas variações foram desenvolvidas a partir do trabalho de Akao e lshihara, em especial para diminuir o número de etapas e facilitar sua aplicação, a exemplo do modelo de quatro fases do American Supplier Institute (CLAUSING, 1994) e do modelo de sete matrizes proposto por Ribeiro, Echeveste e Danilevicz (2001). Embora o QFD seja amplamente utilizado no meio industrial há décadas, ainda são conduzidas pesquisas sobre sua aplicação no desenvolvimento de produtos, a exemplo dos recentes trabalhos de Dikmen, Birgonul e Kiziltas (2005), Marsot (2005), Melo Filho e Cheng (2007) e Miguel (2009).

A flexibilidade do QFD também permite sua aplicação em outras situações, bem como sua integração a diferentes técnicas para a otimização do métodos e a aquisição de benefícios específicos. Os trabalhos de Chen, Fung e Tang (2006), Hanumaiah, Ravi e Mukherjee (2006), Kahraman, Ertay e Büyüközkan (2006), Bottani e Rizzi (2006), Chen e Weng (2006), Bevilacqua, Ciarapica e Giacchetta (2006) e Lai, Tan e Xie (2007), por exemplo, apresentam propostas para a otimização quantitativa do método. Seguindo outra linha, Pramod et al. (2006), Chakraborty e Dey (2007) e Kwong et al. (2007) utilizam o QFD para a melhoria de processos. Os trabalhos de Killen, Walker e Hunt (2005), LePrevost e Mazur (2005), Bosch e Enríquez (2005), Fabri e Carvalho (2005) e Moraes e Miguel (2007), por sua vez, apresentam o QFD como uma ferramenta de gestão.

Além disso, nos últimos anos, diversos pesquisadores vêm empregando o QFD também para a aquisição de benefícios ambientais. Neste sentido, o Comitê Japonês de Design Ambiental redige um manual com recomendações para a aplicação de um QFD ambiental, denominado QFDE - Quality Function Deployment for Environment (MASUI; SAKA0; INABA, 2001). Halog, Schultmann e Rentz (2001) utilizam o QFD para identificar a emissão de substâncias tóxicas baseado em seu impacto ambiental, de forma a concentrar esforços nos pontos críticos de emissão de poluentes. Sakao, Watanabe e Shimomura (2003), por sua vez, aplicam o QFD na avaliação de serviços em um processo de ecodesign. Heejeong e Herrmann (2003) desenvolvem um sistema para extrair a ecovoz do consumidor a partir do modelo convencional de QFD, facilitando o desenvolvimento de ecoprodutos. Strasser e Wimmer (2003) implementam um sistema baseado na web que relaciona requisitos ambientais dos clientes com parâmetros técnicos de design, facilitando o trabalho dos desenvolvedores de produto. Abele, Anderl e Birkhofer (2005) e Kobayashi et al. (2005), por sua vez, desenvolvem diferentes métodos que integram o QFD com a análise do ciclo de vida de produtos, do inglês Life-Cycle Assessment (LCA).

A maioria desses trabalhos, no entanto, está focada apenas na redução dos impactos ambientais, em detrimento das demais dimensões da sustentabilidade, 
sendo incipiente o uso do QFD para esse propósito. A proposta teórica de Edgeman e Hensler (2005) é uma das poucas encontradas na literatura. Nesse trabalho, os autores apresentam o que chamam de "paradigma BEST' (Biophysical/Environmental, Economic, Social e Technical/Technological Sustainability) e propõem sua inclusão ao QFD de forma a correlacionar os princípios BEST às demandas do consumidor já priorizadas. No entanto, o artigo não apresenta exemplos e a proposta parece ser de difícil implementação, uma vez que não foram encontradas publicações posteriores com sua aplicação.

Há, ainda, na literatura, outras propostas que utilizam apenas uma matriz, semelhante às matrizes do QFD, para a avaliação inicial da sustentabilidade de produtos e processos, como apresentado por Goldani et al. (2007), Ribeiro et al. (2007) e Marx e Paula (2008). Embora seja possivel a integração desse tipo de matriz ao QFD, especialmente devido à estrutura similar, essa possibilidade não está apresentada na literatura até o momento.

\subsection{Matriz do indice $S$}

A matriz para a geração do índice de sustentabilidade, ou Matriz do Índice $S$, apresentada no trabalho de Marx e Paula (2008) é uma adaptação da proposta original de Goldani et al. (2007). Essa matriz apresenta-se como uma ferramenta de suporte à decisão para auxiliar a seleção de materiais nas fases iniciais do PDP. Ao serem inseridas na matriz, as matérias-primas podem ser avaliadas de acordo com os impactos gerados sobre o meio ambiente, sobre a sociedade e sobre o processo produtivo em todos os estágios de uso e transformação.

A matriz utiliza os pesos definidos por Goldani et al. (2007) para dez critérios de sustentabilidade, pesos estes resultantes de uma comparação pareada de atributos em relação à sua importância na tomada de decisão e apresentados na Tabela 1.

Entretanto, Marx e Paula (2008) consideram que os impactos humanos, os impactos ambientais e a geração de resíduos são diferentes ao longo da cadeia produtiva e de consumo, não sendo possível avaliar esses critérios de forma generalizada. Dessa forma, na Matriz do Índice $S$, os pesos atribuídos para esses critérios foram divididos igualmente, considerando igualmente importantes os impactos sobre os usuários primários, secundários e finais, bem como os impactos ambientais e a geração de resíduos dos processos de obtenção, transformação e descarte de matérias-primas. Os critérios de sustentabilidade usados na matriz, os pesos atribuídos a cada um deles e a sua respectiva descrição estão descritos na Tabela 1.

Tabela 1. Requisitos agrupados em critérios de sustentabilidade (GOLDAN1 et al., 2007; MARX; PAULA, 2008).

\begin{tabular}{|c|c|c|c|}
\hline Critério & $\begin{array}{l}\text { Usuário/ } \\
\text { processo }\end{array}$ & Peso & Descrição \\
\hline \multirow{3}{*}{$\begin{array}{l}\text { Impacto } \\
\text { humano }\end{array}$} & Primário & 0,014 & $\begin{array}{l}\text { Efeitos sobre os usuários envolvidos na obtenção da matéria-prima: Atoxidade e riscos patológicos } \\
\text { (teratogenicidade, mutogenicidade) }\end{array}$ \\
\hline & Intermediário & 0,014 & $\begin{array}{l}\text { Efeitos sobre os usuários envolvidos na fabricação do produto: Atoxidade e riscos patológicos } \\
\text { (teratogenicidade, mutogenicidade) }\end{array}$ \\
\hline & Final & 0,014 & $\begin{array}{l}\text { Efeitos sobre o consumidor final: } \\
\text { Atoxidade e riscos patológicos (teratogenicidade, mutogenicidade) }\end{array}$ \\
\hline \multirow{3}{*}{$\begin{array}{l}\text { Impacto } \\
\text { ambiental }\end{array}$} & Obtenção & 0,057 & Ser um recurso renovável; ser ecologicamente correto \\
\hline & Transformação & 0,057 & Ser inócuo ao meio ambiente; ser ecologicamente correto \\
\hline & Descarte & 0,057 & Ser reciclável; ser biodegradável; ser ecologicamente correto \\
\hline \multirow{3}{*}{$\begin{array}{l}\text { Geração } \\
\text { de } \\
\text { resíduos }\end{array}$} & Obtenção & 0,038 & $\begin{array}{l}\text { Resíduos específicos do processo de obtenção das matérias-primas: } \\
\text { Facilidade de eliminação no meio; número de subprodutos gerados; tipo de subprodutos gerados }\end{array}$ \\
\hline & Transformação & 0,038 & $\begin{array}{l}\text { Resíduos específicos do processo de fabricação dos produtos: } \\
\text { Facilidade de eliminação no meio; número de subprodutos gerados; tipo de subprodutos gerados }\end{array}$ \\
\hline & Descarte & 0,038 & $\begin{array}{l}\text { Resíduos específicos do processo de descarte dos produtos: } \\
\text { Facilidade de eliminação no meio; número de subprodutos gerados; tipo de subprodutos gerados }\end{array}$ \\
\hline \multicolumn{2}{|c|}{ Qualidade } & 0,085 & $\begin{array}{l}\text { Resistência; durabilidade; variabilidade; flexibilidade; maleabilidade; aroma; volume; conforto; } \\
\text { rendimento; vida útil; necessidade de manutenção }\end{array}$ \\
\hline \multicolumn{2}{|c|}{ Processo facilitado } & 0,068 & $\begin{array}{l}\text { Segurança no processo; simplicidade no processo; facilidade de manuseio/trabalho; facilidade de controle } \\
\text { do processo }\end{array}$ \\
\hline \multicolumn{2}{|c|}{ Disponibilidade } & 0,057 & $\begin{array}{l}\text { Disponibilidade regional; facilidade de aquisição, obtenção; abundância; logística/distribuição; confiança } \\
\text { nos fornecedores, nos prazos de entrega e no ajuste das especificações }\end{array}$ \\
\hline \multicolumn{2}{|r|}{ Custo } & 0,049 & Preço; custo de obtenção; custo-benefício \\
\hline \multicolumn{2}{|c|}{ Usabilidade } & 0,043 & Facilidade de uso em diferentes aplicações; adaptabilidade quanto ao processo; adequação ao que se destina \\
\hline \multicolumn{2}{|c|}{ Boa aparência } & 0,038 & Cor; beleza; valor estético agregado \\
\hline \multicolumn{2}{|c|}{ Mercado consumidor } & 0,044 & Adequado aos requisitos do cliente, aceitação no mercado, demanda \\
\hline \multicolumn{2}{|r|}{ Total $=$} & 1 & \\
\hline
\end{tabular}


Para o preenchimento da matriz de geração de índice de sustentabilidade, apresentada na Tabela 2, devem ser estabelecidas as intensidades do relacionamento entre as matérias-primas e os critérios de seleção. 0 estabelecimento dessas relações deve ser feito respondendo à seguinte pergunta: "qual o impacto da matéria-prima ( $i$ ) em relação ao critério (j)?' e utilizando os pesos sugeridos por Mizuno e Akao (1994), em que (9) indica um relacionamento forte, (3) indica um relacionamento médio e (1) indica um relacionamento fraco.

0 índice de sustentabilidade (Índice $S$ ) é calculado considerando a intensidade dos relacionamentos entre cada função $\left(P Q_{i j}\right)$ e o peso atribuído para cada um dos $n$ critérios $\left(\mathrm{W}_{j}\right)$, de acordo com a Equação 1.

$$
\text { Indice } S=\sum_{j=1}^{n} P Q_{i j} \times W_{j}
$$

0 Índice $S$ resultante da matriz pode, então, ser aplicado para a comparação individual das matériasprimas, no redesenho de produtos existentes e no projeto de novos produtos mais sustentáveis. A matriz demonstra potencial de aplicação como filtro ambiental, para a definição de metas de melhoria baseadas no aumento do índice de sustentabilidade dos novos produtos, bem como na orientação da equipe de desenvolvimento (MARX; PAULA, 2008).

Embora o preenchimento da matriz seja simples, foi verificada a importância de uma equipe multifuncional e com alto nível de especialização para a avaliação técnica das matérias-primas.

\section{Método de pesquisa}

Em relação ao objetivo geral, esta é uma pesquisa exploratória, focada no teste de um modelo de QFD. De acordo com Gil (2007), as pesquisas exploratórias são usadas para conhecer melhor um problema, de forma a torná-lo explícito ou a construir hipóteses por meio de levantamento bibliográfico, entrevistas e análise de exemplos. Em relação ao procedimento técnico, foi utilizado um estudo de caso.

Inicialmente, adaptou-se o modelo de QFD (RIBEIRO; ECHEVESTE; DANILEVICZ, 2001), de forma a incorporar a Matriz do Índice $S$ e alinhar o trabalho à lógica sustentável por meio da avaliação da sustentabilidade das matérias-primas. Além disso, foi inserido outro mecanismo para aumentar a sustentabilidade do produto final, por meio da redução de partes na matriz dos componentes. A Figura 1 apresenta o modelo descritivo utilizado neste trabalho, com a descrição de suas etapas.

0 modelo inicia com o levantamento dos requisitos do cliente (1) com a aplicação de uma pesquisa de mercado para captar a voz do cliente e formar a árvore da qualidade demandada. Em seguida, essas informações são convertidas em requisitos do produto na matriz da qualidade (2), que é desdobrada em duas matrizes independentes, uma de componentes (3) e a outra de processos (7).

Neste trabalho, a matriz de componentes (3) está empregada em substituição à matriz das partes tradicionalmente utilizada no QFD. lsso é motivado pela natureza do produto em questão, que não possui partes que possam ser desmembradas, mas componentes da fórmula que exercem funções específicas no produto final. Em virtude da grande quantidade de componentes que podem ser empregados na formulação de um produto domissanitário, foi utilizado um indice $\left(I P_{i}^{*}\right)$ para priorizar os componentes da fórmula, permitindo identificar quais deles poderiam ser suprimidos com o mínimo de perda da qualidade demandada para o produto. A eliminação de partes desnecessárias é uma das diretrizes do ecodesign e do DfE para o projeto de produtos de menor impacto ambiental, permitindo reduzir o consumo de materiais e facilitando a montagem, a desmontagem e a reciclagem do produto (BREZET; HEMEL, 1997; MANZINI; VEZZOLI, 2005). De acordo com Ribeiro, Echeveste e Danilevicz (2001), nesta etapa do QFD

Tabela 2. Matriz do Índice S (MARX; PAULA, 2008).

\begin{tabular}{|c|c|c|c|c|c|c|c|c|c|c|c|c|c|c|c|c|c|}
\hline \multirow{3}{*}{ 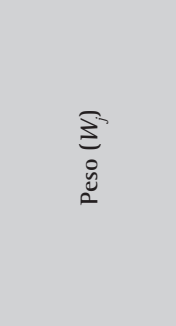 } & 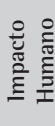 & & & 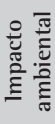 & & & 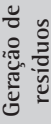 & & & \multirow{2}{*}{$\frac{\frac{\pi}{0}}{\frac{\pi}{0}}$} & \multirow{2}{*}{ 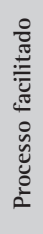 } & \multirow{2}{*}{ 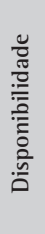 } & \multirow{2}{*}{$\frac{0}{\tilde{n}}$} & \multirow{2}{*}{ 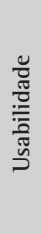 } & \multirow{2}{*}{ 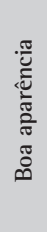 } & \multirow{2}{*}{ 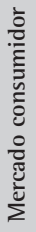 } & \multirow{2}{*}{$\begin{array}{l}n \\
\stackrel{.}{\circ} \\
.0\end{array}$} \\
\hline & $\dot{\Xi}$ & $\frac{E}{E}$ & 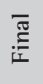 & ठ̊. & 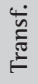 & 巳ٌ̊ & 远 & $\frac{4}{\tilde{n}}$ & ஹٌ & & & & & & & & \\
\hline & $\frac{ \pm}{0}$ & $\frac{ \pm}{0}$ & $\frac{ \pm}{0}$ & $\begin{array}{l}\hat{10} \\
\circ \\
0\end{array}$ & $\begin{array}{l}\hat{10} \\
\circ \\
0\end{array}$ & $\begin{array}{l}\hat{L} \\
0 \\
0\end{array}$ & $\begin{array}{l}\infty \\
\stackrel{\infty}{0} \\
0 \\
0\end{array}$ & $\begin{array}{l}\infty \\
\stackrel{\infty}{0} \\
0\end{array}$ & $\begin{array}{c}\infty \\
\hat{0} \\
0\end{array}$ & $\begin{array}{l}\text { L } \\
\infty \\
0 \\
0 \\
0\end{array}$ & $\begin{array}{l}\infty \\
0 \\
0 \\
0 \\
0\end{array}$ & $\begin{array}{l}\hat{10} \\
0 \\
0\end{array}$ & $\begin{array}{l}\text { g } \\
\text { O } \\
0\end{array}$ & $\begin{array}{l}\text { भे } \\
0 \\
0\end{array}$ & 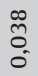 & $\begin{array}{l}\text { ஸे } \\
\text { Oे }\end{array}$ & ᄋ \\
\hline Matéria-prima 1 & 3 & 3 & 9 & 3 & 3 & 9 & 1 & 9 & 3 & 3 & 9 & 9 & 9 & 9 & 3 & 9 & 5 \\
\hline Matéria-prima 2 & 1 & 3 & 9 & 3 & 3 & 9 & 1 & 9 & 9 & 3 & 9 & 9 & 9 & 9 & 9 & 9 & 5 \\
\hline Matéria-prima 3 & 1 & 9 & 9 & 1 & 9 & 9 & 1 & 9 & 9 & 9 & 9 & 9 & 3 & 9 & 9 & 9 & 5 \\
\hline
\end{tabular}




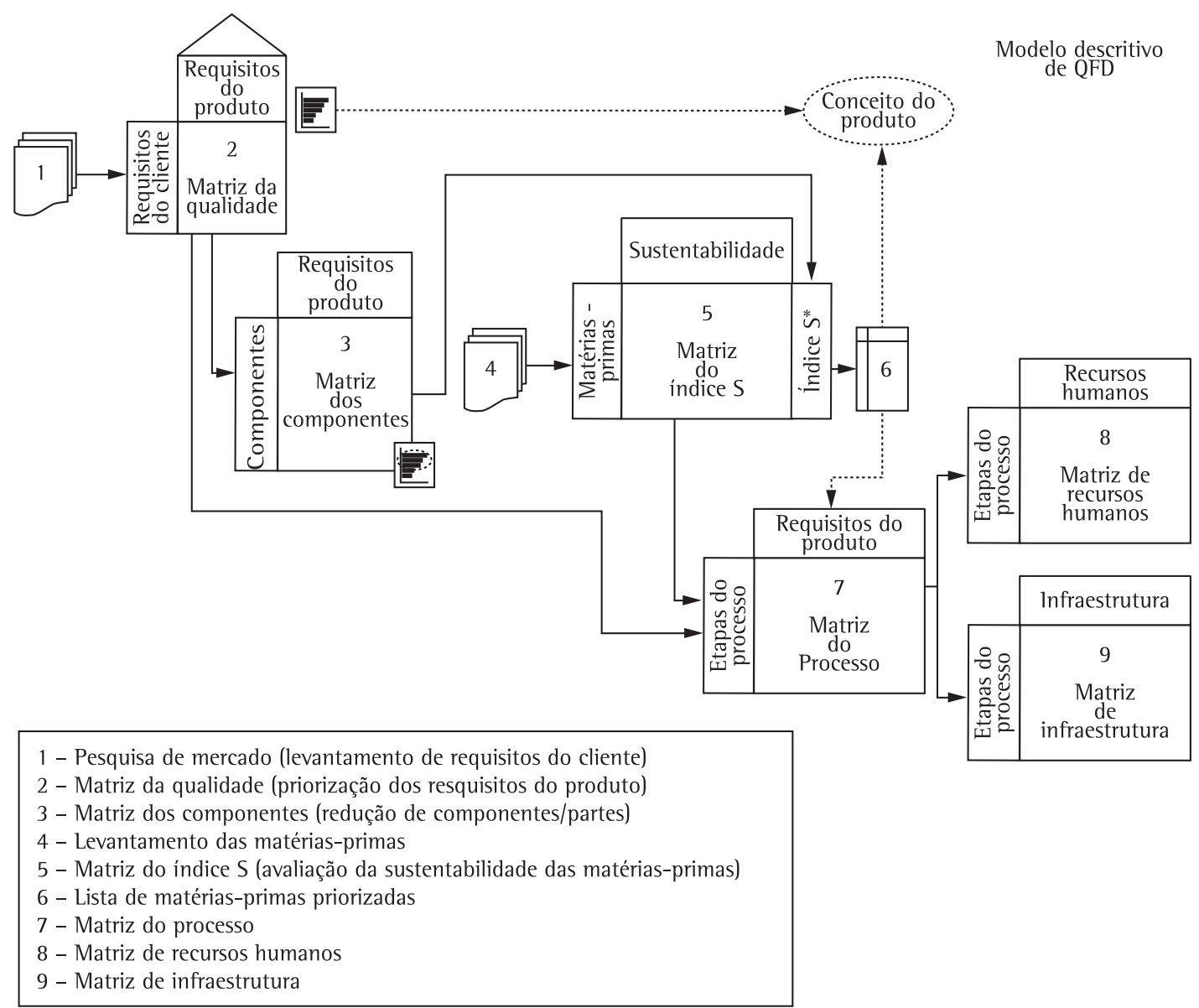

Figura 1. Modelo descritivo de QFD.

devem ser avaliados a dificuldade e o tempo de implantação de melhorias, o que permite adequar o peso dos requisitos do cliente à capacidade da empresa em atendê-los. Para tanto, são empregados dois fatores, um para cada um desses aspectos. Neste ponto, foi feita uma alteração nos indicadores que avaliam tais aspectos: a dificuldade e o tempo de implantação foram agrupados em uma única variável $\left(F_{i}\right)$ e a importância de cada componente para o produto final foi avaliada por uma nova variável $\left(F D_{j}\right)$.

Em seguida, é feito um levantamento das matériasprimas (4) correspondentes aos componentes que não foram eliminados. Esse levantamento serve de entrada para a Matriz do Índice $S$ (5), utilizada para a avaliação dos impactos das matérias-primas em relação à sustentabilidade, de acordo com os critérios definidos por Goldani et al. (2007) e apresentados no referencial teórico deste trabalho. 0 índice $S$ resultante é, então, ponderado em relação à importância relativa de cada componente para o produto final $\left(I P_{i}^{*}\right)$, obtendo-se $o$ índice de sustentabilidade ponderado (Índice $S^{*}$ ) para as matérias-primas. Os dados resultantes dessa matriz são, então, organizados na forma de lista, com as matérias-primas subdivididas por componente da fórmula e priorizadas em função dos índices obtidos (6). As informações resultantes das etapas 2 e 5 são usadas, posteriormente, para a definição do conceito do novo produto.

A matriz do processo (7) é construída após a geração do conceito do produto. Essa matriz é utilizada para avaliar a relação entre os processos e as características de qualidade do produto, de forma a priorizar os processos que mais influenciam as características de qualidade que devem ser alteradas. A saída dessa matriz é utilizada para a geração das matrizes de recursos humanos (8) e de infraestrutura (9), que possibilitam avaliar os custos de implementação da melhoria de cada processo. 0 modelo descritivo contempla, ainda, a possibilidade de alteração dos processos em função da seleção das matérias-primas.

As métricas empregadas nas matrizes do QFD (RIBEIRO; ECHEVESTE; DANILEVICZ, 2001) são apresentadas a seguir, juntamente com os resultados da aplicação do método. Todas as matrizes apresentadas 
neste trabalho utilizam, em seu preenchimento, os pesos sugeridos por Mizuno e Akao (1994), em que (9) indica um relacionamento forte, (3) indica um relacionamento médio e (1) indica um relacionamento fraco.

\section{Detergente sustentável: resultados e discussão}

0 estudo de caso apresentado a seguir, apresenta a aplicação do método descrito apenas até a Etapa 6, uma vez que a maior contribuição deste trabalho está na aplicação das matrizes da qualidade, de componentes e da Matriz do Índice $S$. As demais matrizes apresentadas no modelo descritivo (processo e recursos), bem como o resultado conceitual do detergente não são detalhados neste artigo.

Esta pesquisa foi conduzida no âmbito do projeto de pesquisa 'Desenvolvimento de Produtos Sustentáveis em Ambiente do Product Service System? 0 tema dessa proposta é o desenvolvimento de produtos sustentáveis concebidos através de uma visão sistêmica, para atender a necessidades de higiene e saúde. Nesta proposta são apresentadas duas frentes de trabalho, incluindo um sistema de uso de fraldas biodegradáveis em ambiente hospitalar e um sistema de limpeza doméstica. Ambos os sistemas pressupõem o desenvolvimento físico de produtos (fralda e detergente biodegradáveis), os quais se encontram em estágios diferentes de desenvolvimento.

Este estudo está relacionado com as fases de projeto informacional e conceitual do sistema de limpeza, mais precisamente um detergente sustentável para a lavagem de louças. Para esta etapa do projeto, os pesquisadores definiram as seguintes metas a serem alcançadas: i) reduzir os componentes do produto em $20 \%$ em relação aos produtos existentes no mercado e produzidos pelos parceiros, e ii) empregar matériasprimas mais sustentáveis.

\subsection{Levantamento dos requisitos do cliente}

0 ponto de partida deste trabalho foi uma pesquisa de mercado na qual foram identificadas as demandas dos clientes, usadas na elaboração da árvore da qualidade demandada. Essa pesquisa foi realizada em duas etapas: uma qualitativa e uma quantitativa. É importante ressaltar que, devido à natureza exploratória desta pesquisa, o número de pessoas entrevistadas nesta etapa foi bastante reduzido. Em futuros estudos não exploratórios, no entanto, a pesquisa de mercado deverá ser realizada em maior profundidade. De acordo com Cheng e Melo Filho (2007), na fase de pesquisa qualitativa, por exemplo, devem ser entrevistadas mais de vinte pessoas ou realizados três grupos focais com oito componentes cada.
A etapa qualitativa da pesquisa teve como objetivo identificar as principais demandas dos clientes em relação a produtos para a limpeza de louças. Ao todo, foram entrevistadas oito pessoas, sendo que as respostas passaram a se repetir após o quinto entrevistado, o que definiu a conclusão da etapa de coleta de dados. Os entrevistados foram convidados a responder a perguntas sobre: i) o tipo de produto usado para limpar a louça; ii) as características desejadas em um produto para limpar a louça; iii) os motivos para não comprar outros produtos para limpar a louça; iv) razões para a escolha de um determinado produto; e v) a importância da biodegradabilidade do produto na hora da compra. As demandas (também chamadas de requisitos dos clientes) identificadas nesta fase foram desdobradas e organizadas em três níveis: primário, secundário e terciário, formando a árvore da qualidade demandada apresentada na Tabela 3.

A etapa quantitativa tem como objetivo identificar a ordem de importância das características demandadas pelos clientes para um detergente, possibilitando a realização de trade-offs entre esses requisitos. Para tanto, foi montado um questionário quantitativo baseado na árvore da qualidade demandada construída na etapa anterior (Apêndice 1). Uma amostra de vinte e cinco $(n=25)$ pessoas que utilizam regularmente detergentes para a limpeza de louças foi instruída a classificar os itens do nível terciário com valores de 1 a 10, em que 1 significa sem importância e 10 significa muito importante. Posteriormente, os entrevistados foram convidados a preencher uma questão final, na qual deveriam enumerar em ordem de preferência as seguintes características secundárias: ter um bom rendimento, capacidade de limpeza, ter uma boa aparência, ser fácil de usar, não prejudicar a natureza e ser acessível. Esses itens referem-se ao nível secundário e foram numerados de 1 (mais importante) a 6 (menos importante), sem repetições.

A Tabela 3 apresenta o desdobramento dos itens de qualidade e seus respectivos pesos relativos. Os pesos referentes aos itens do nível secundário foram obtidos a partir da questão final do questionário quantitativo (questão de ordenar). Para esta questão, a medida resumo utilizada foi a soma do inverso da ordem atribuída pelos entrevistados. Os pesos referentes ao nível terciário, por sua vez, foram obtidos pela média das respostas das primeiras seis questões do questionário. Após o cálculo do peso de cada característica do produto, calculou-se o peso relativo (\%) utilizado na matriz da qualidade como o índice $I D_{i}$.

A última coluna à direita apresenta o peso obtido pela distribuição do peso relativo do nível secundário nos níveis terciários que o compõe. Note que a soma dos pesos dos níveis terciários equivalem ao 
Tabela 3. Árvore da qualidade demandada, apresentando o desdobramento dos requisitos do cliente e seus respectivos pesos (\%).

\begin{tabular}{|c|c|c|c|c|c|}
\hline $\begin{array}{c}\text { Nivel } \\
\text { Primário } \\
\end{array}$ & Nível Secundário & Peso\% & Nível Terciário & Peso & Peso\% (ID $)$ \\
\hline \multirow{20}{*}{ 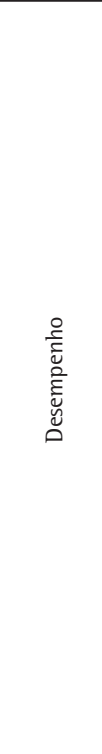 } & \multirow{4}{*}{ Rendimento } & \multirow{3}{*}{17,46} & Facilidade de espalhar & 8,204 & 5,65 \\
\hline & & & Durabilidade do produto em condições de uso & 8,121 & 5,59 \\
\hline & & & Que utiliza pequenas quantidades para realizar a limpeza & 9,102 & 6,26 \\
\hline & & & & 25,427 & $(17,46)$ \\
\hline & \multirow{3}{*}{ Capacidade de limpeza } & \multirow{3}{*}{25,96} & Capacidade desengordurante & 9,259 & 8,91 \\
\hline & & & Capacidade de remover sujeira & 9,338 & 8,99 \\
\hline & & & Capacidade de remover cheiro & 8,385 & 8,07 \\
\hline & & & & 26,981 & $(25,96)$ \\
\hline & \multirow{3}{*}{$\begin{array}{c}\text { Produto } \\
\text { (características físicas) }\end{array}$} & \multirow{3}{*}{13,27} & Cor agradável & 6,000 & 3,68 \\
\hline & & & Cheiro agradável & 7,685 & 4,71 \\
\hline & & & Consistência líquida & 7,962 & 4,88 \\
\hline & & & & 21,648 & $(13,27)$ \\
\hline & \multirow{3}{*}{$\begin{array}{c}\text { Produto } \\
\text { (características de uso) }\end{array}$} & \multirow{3}{*}{11,72} & Ter pH neutro (ser suave para as mãos) & 8,525 & 4,07 \\
\hline & & & Dar brilho & 8,063 & 3,85 \\
\hline & & & Fazer espuma & 7,974 & 3,80 \\
\hline & & & & 24,562 & $(11,72)$ \\
\hline & \multirow{3}{*}{ Características sanitárias } & \multirow{3}{*}{20,26} & Produto biodegradável & 9,267 & 6,78 \\
\hline & & & Ser hipoalergênico & 8,957 & 6,56 \\
\hline & & & Aprovado pela vigilância sanitária & 9,456 & 6,92 \\
\hline & & & & 27,680 & $(20,26)$ \\
\hline \multirow{5}{*}{ 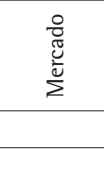 } & \multirow{3}{*}{$\begin{array}{l}\text { Características de } \\
\text { mercado }\end{array}$} & \multirow{3}{*}{11,34} & Preço competitivo & 8,212 & 4,11 \\
\hline & & & Reconhecimento na mídia das características do produto & 7,704 & 3,86 \\
\hline & & & Qualidade (reconhecimento da marca) & 6,736 & 3,37 \\
\hline & & & & 22,652 & $(11,34)$ \\
\hline & & $\Sigma=100 \%$ & & & $\Sigma=100 \%$ \\
\hline
\end{tabular}

percentual atribuído ao total do peso dos níveis secundários. Assim, o peso do atributo rendimento, por exemplo, representa $17,46 \%$ da importância relativa do produto, distribuída entre 'facilidade de espalhar' (5,65\%), 'durabilidade do produto em condições de uso' (5,59\%) e 'que utiliza pequenas quantidades para limpar' $(6,26 \%)$.

\subsection{Identificação dos requisitos do produto}

Após a construção da árvore da qualidade, a equipe de desenvolvimento identificou quais requisitos do produto poderiam ser associados aos requisitos dos clientes. Essa associação é facilitada quando há um conhecimento prévio a respeito das características do produto que está sendo desenvolvido, como é o caso do detergente. De maneira geral, pode-se dizer que os requisitos do produto apresentam um caráter funcional, estando associados às funções técnicas do produto, enquanto os requisitos dos clientes são de caráter não funcional, associados ao desempenho do produto como um todo (MARX, 2009).

No QFD, essa identificação dos requisitos do produto por meio dos requisitos dos clientes é denominada desdobramento da qualidade demandada, realizada na matriz da qualidade. Nesta matriz, os pesos dos requisitos dos clientes obtidos na etapa anterior $\left(I D_{i}\right)$ são corrigidos por meio de uma avaliação competitiva $\left(M_{i}\right)$ e de uma avaliação estratégica $\left(E_{i}\right)$ em relação aos produtos concorrentes. 0 resultado desse benchmarking é o índice de importância corrigido $\left(I D_{i}^{*}\right)$, calculado de acordo com a Equação 2.

$$
I D_{i}^{*}=I D_{i} \times \sqrt{E_{i}} \times \sqrt{M_{i}}
$$

Além da correção dos pesos atribuídos aos requisitos do cliente, nessa matriz é feita a determinação da importância dos requisitos do produto $\left(I Q_{j}\right)$, considerando sua relação com os requisitos do cliente $\left(D Q_{i j}\right)$ e a importância relativa destes $\left(I D_{i}{ }^{*}\right)$. Como explicado no final da seção 3, no cálculo do $D Q_{i j}$ é utilizada a escala do grau de relação $0,1,3$ e 9. A fórmula empregada está apresentada na Equação 3. Para facilitar a visualização dos resultados na matriz da qualidade, todos os resultados desta Equação foram divididos pelo fator 10, o que não influencia o resultado final.

$$
1 Q j=\sum_{i=1}^{n} I D_{i}^{*} \times D Q_{i j}
$$

0 modelo conceitual de QFD utilizado propõe o uso de um fator de ajustar o índice de importância dos requisitos do produto, por meio da avaliação da dificuldade de atuação sobre as características de qualidade $\left(D_{j}\right)$ e uma avaliação competitiva em 
relação às características técnicas $\left(B_{j}\right)$. Foi utilizada a Equação 4.

$$
1 Q_{j}^{*}=1 Q_{j} \times \sqrt{D_{j}} \times \sqrt{B_{j}}
$$

Todas essas avaliações para correção dos índices de importância, tanto dos requisitos do cliente quanto dos requisitos do produto, utilizam uma escala que vai de 0,5 a 2,0. As escalas utilizadas nas avaliações competitivas, na avaliação estratégica e na dificuldade de modificar as especificações técnicas estão apresentadas na Tabela 4.

Para o preenchimento correto da matriz da qualidade, representada na Tabela 5 , seguiu-se a

Tabela 4. Escalas de avaliação dos fatores $M_{i}, E_{i}, D_{i}$ e $B_{i}$.

\begin{tabular}{|c|c|c|c|}
\hline Escala & $\begin{array}{l}\text { Avaliação } \\
\text { competitiva } \\
\left(M_{i} \text { e } B_{j}\right)\end{array}$ & $\begin{array}{l}\text { Avaliação } \\
\text { estratégica } \\
\left(E_{i}\right)\end{array}$ & $\begin{array}{l}\text { Dificuldade } \\
\text { de atuação } \\
\left(D_{j}\right)\end{array}$ \\
\hline 0,5 & $\begin{array}{c}\text { Acima da } \\
\text { concorrência }\end{array}$ & $\begin{array}{l}\text { Importância } \\
\text { pequena }\end{array}$ & $\begin{array}{l}\text { Muito } \\
\text { dificil }\end{array}$ \\
\hline 1,0 & $\begin{array}{l}\text { Similar à } \\
\text { concorrência }\end{array}$ & $\begin{array}{l}\text { Importância } \\
\text { média }\end{array}$ & Difícil \\
\hline 1,5 & $\begin{array}{l}\text { Abaixo da } \\
\text { concorrência }\end{array}$ & $\begin{array}{l}\text { Importância } \\
\text { grande }\end{array}$ & Moderado \\
\hline 2,0 & $\begin{array}{l}\text { Muito abaixo da } \\
\text { concorrência }\end{array}$ & $\begin{array}{l}\text { lmportância } \\
\text { muito grande }\end{array}$ & Fácil \\
\hline
\end{tabular}

seguinte questão: 'quanto este requisito do cliente (i) influencia este requisito do produto $(j)$ ?'

Esta matriz apresenta dois resultados, que correspondem à priorização dos requisitos dos clientes $\left(I D_{i}^{*}\right)$ e à priorização dos requisitos do produto $\left(I Q_{j}^{*}\right)$. Os valores de $I D_{i}^{*}$ referem-se aos requisitos do cliente e serão utilizados posteriormente, na elaboração do conceito do produto. Já os valores de $l Q_{j}^{*}$ indicam a priorização dos requisitos técnicos do produto, e serão utilizados como dados de entrada para as matrizes 3 e 7 do QFD (Figura 1).

A matriz da Tabela 5 apresenta os requisitos do cliente organizados em ordem decrescente de acordo com os valores de $I D_{i}^{*}$, indicando sua priorização. Observa-se que os requisitos do cliente considerados mais importantes são aqueles relacionados à capacidade de limpeza, isto é, ao desempenho do detergente enquanto produto de limpeza. $\mathrm{Na}$ sequência, aparecem os requisitos relacionados à saúde e segurança do produto em relação aos usuários e ao meio ambiente, que constituem restrições para as possíveis soluções de projeto. Isso demonstra que o consumidor deseja um detergente que seja tão eficiente quanto sustentável.

Tabela 5. Visão parcial da matriz da qualidade.

\begin{tabular}{|c|c|c|c|c|c|c|c|c|c|c|}
\hline & & \multicolumn{5}{|c|}{ REQUISITOS DO DETERGENTE } & \multirow[b]{2}{*}{$I D_{i}$} & \multirow[b]{2}{*}{$E_{i}$} & \multirow[b]{2}{*}{$M_{i}$} & \multirow[b]{2}{*}{$I D_{i}^{*}$} \\
\hline & & Rendimento & $\begin{array}{l}\text { Teor de } \\
\text { tensoativo }\end{array}$ & Viscosidade & Estabilidade (...) & $\begin{array}{l}\text { Irritação } \\
\text { dérmica }\end{array}$ & & & & \\
\hline \multirow{18}{*}{ 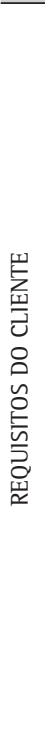 } & Capacidade de remover sujeira & & 9 & & & & 8,99 & 2,0 & 1,0 & 12,71 \\
\hline & Capacidade desengordurante & & 9 & & & & 8,91 & 2,0 & 1,0 & 12,60 \\
\hline & Aprovado pela vigilância sanitária & & 1 & & & & 6,92 & 2,0 & 1,0 & 9,79 \\
\hline & Produto biodegradável & & & & & & 6,78 & 2,0 & 1,0 & 9,59 \\
\hline & Ser hipoalergênico & & & & & 9 & 6,56 & 2,0 & 1,0 & 9,27 \\
\hline & $\begin{array}{l}\text { Que utiliza pequenas quantidades } \\
\text { para realizar a limpeza }\end{array}$ & 9 & 9 & 3 & & & 6,26 & 2,0 & 1,0 & 8,86 \\
\hline & Capacidade de remover cheiro & & 3 & & & & 8,07 & 1,0 & 1,0 & 8,07 \\
\hline & Facilidade de espalhar & 3 & & 3 & & & 5,65 & 2,0 & 1,0 & 7,98 \\
\hline & $\begin{array}{l}\text { Durabilidade do produto em condições } \\
\text { de uso }\end{array}$ & 9 & 3 & 9 & 9 & & 5,59 & 2,0 & 1,0 & 7,90 \\
\hline & Ter pH neutro (ser suave para as mãos) & & & & & 9 & 4,07 & 2,0 & 1,0 & 5,75 \\
\hline & Preço competitivo & 1 & 9 & & & 3 & 4,11 & 1,5 & 1,0 & 5,03 \\
\hline & Consistência líquida & 1 & 1 & 9 & & & 4,88 & 1,0 & 1,0 & 4,88 \\
\hline & Qualidade (reconhecimento da marca) & 9 & 3 & 3 & 9 & 3 & 3,37 & 2,0 & 1,0 & 4,77 \\
\hline & $\begin{array}{l}\text { Reconhecimento na mídia das } \\
\text { características do produto }\end{array}$ & & & & & & 3,86 & 1,5 & 1,0 & 4,72 \\
\hline & Cheiro agradável & & & & & 1 & 4,71 & 0,5 & 1,0 & 3,33 \\
\hline & Dar brilho & & & & & & 3,85 & 0,5 & 1,0 & 2,72 \\
\hline & Fazer espuma & & 1 & & & & 3,80 & 0,5 & 1,0 & 2,69 \\
\hline & Cor agradável & & & & & 1 & 3,68 & 0,5 & 1,0 & 2,60 \\
\hline \multicolumn{2}{|c|}{ Especificações } & 4 a 7 pratos & $>7 \%$ & $>100 \mathrm{cP}$ & $<0^{\circ} \mathrm{C}$ & Negativo & & & & \\
\hline \multicolumn{2}{|c|}{$1 Q_{j}$} & 22,77 & 43,24 & 17,99 & 11,41 & 17,05 & & & & \\
\hline \multicolumn{2}{|c|}{ Dificuldade de atuação $\left(D_{j}\right)$} & 1,50 & 1,50 & 0,50 & 2,00 & 1,00 & & & & \\
\hline \multicolumn{2}{|c|}{ Avaliação competitiva $\left(B_{j}\right)$} & 1,00 & 1,00 & 1,00 & 1,00 & 1,00 & & & & \\
\hline \multicolumn{2}{|c|}{$1 Q_{j}^{*}$} & 27,88 & 52,96 & 12,72 & 16,13 & 17,05 & & & & \\
\hline
\end{tabular}




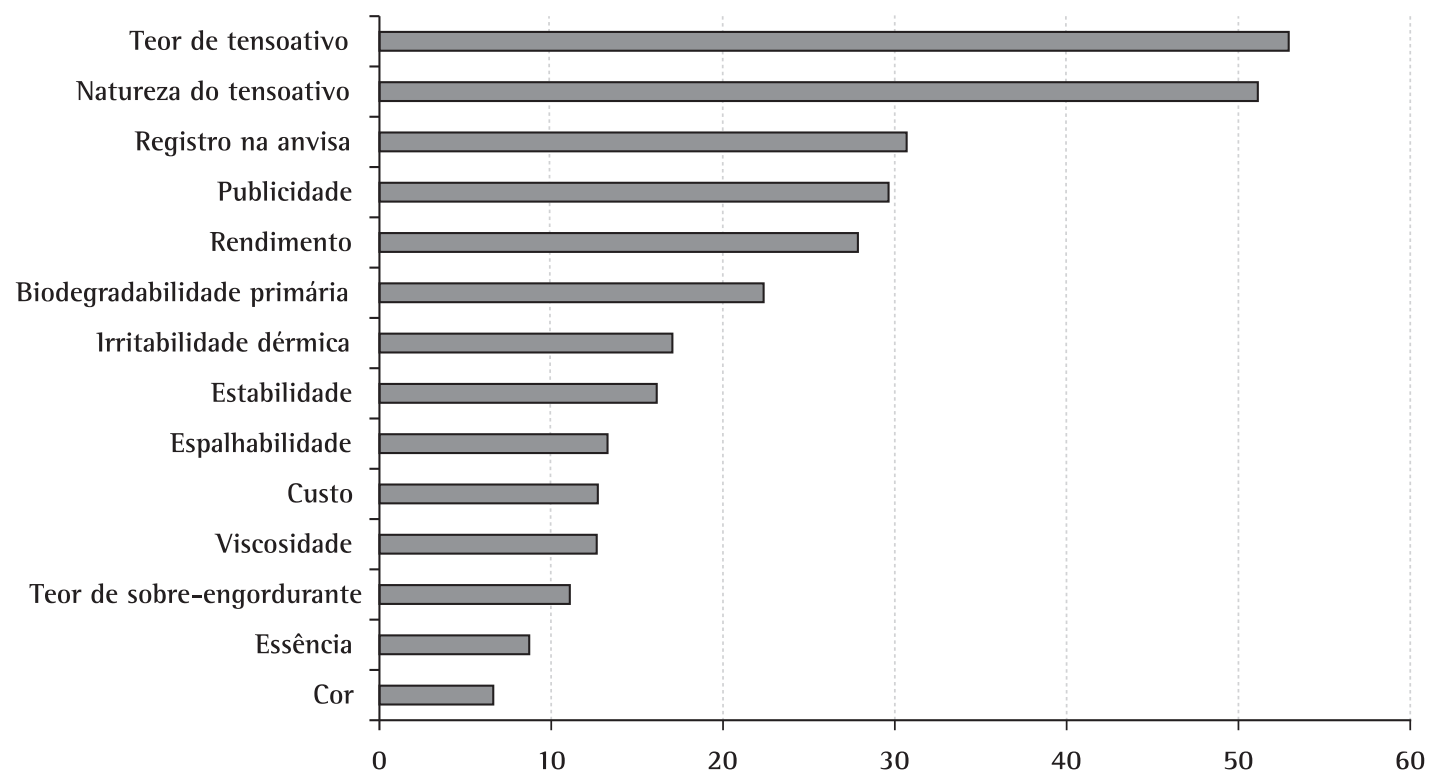

Figura 2. Gráfico mostrando a priorização dos requisitos técnicos do produto.

A matriz apresenta, também, que as características do produto pouco valorizadas pelos clientes são aquelas relacionadas às funções estéticas e simbólicas do produto, como cor, aroma e marca (branding), bem como às funções práticas secundárias, como a capacidade de dar brilho à louça. De acordo com os resultados, não é necessário despender esforços em relação à aparência e a benefícios secundários do detergente, uma vez que esses fatores são pouco valorizados pelos clientes e, portanto, pouco contribuirão para a sua futura aceitação no mercado.

A Figura 2 apresenta um gráfico com o resultado da priorização dos requisitos do detergente $\left(1 Q_{j}^{*}\right)$ realizada na matriz da qualidade. 0 gráfico demonstra que os requisitos relacionados às características do tensoativo apresentam uma importância relativa muito superior aos demais requisitos técnicos, o que se justifica por estarem diretamente relacionados à principal função do produto, isto é, a capacidade de limpeza. Nota-se que isso reafirma os resultados obtidos na priorização dos requisitos do cliente (coluna $I D_{i}^{*}$ da Tabela 5), uma vez que as características de qualidade consideradas mais importantes pelos clientes devem-se ao desempenho dos requisitos técnicos priorizados. Da mesma forma, é possível observar que as os requisitos do produto considerados relativamente menos importantes são os que correspondem a funções secundárias e a funções estéticas, corroborando os resultados da priorização dos requisitos dos clientes.

Após a priorização, os requisitos do produto com seus respectivos índices $l Q_{j}^{*}$ foram utilizados como entrada para a matriz de componentes, cujo desdobramento é apresentado a seguir.

\subsection{Redução de componentes/partes}

Após a identificação e a avaliação dos requisitos do produto na matriz da qualidade, a equipe de desenvolvimento de produto listou os componentes relacionados às possíveis funções do produto. Esses componentes são: tensoativo, espumante, sobreengordurante, umectante, hidrótopo, espessante, corante, essência, agente tampão, antioxidante, sequestrante, regulador de $\mathrm{pH}$, antimicrobiano, eliminador de proteínas e veículo.

A importância de cada um desses componentes $\left(I P_{i}\right)$ considerou a intensidade dos relacionamentos entre cada componente $\left(P Q_{i j}\right)$ e a importância definida para as características de qualidade $\left(1 Q_{j}^{*}\right)$. Essa importância foi atribuída por meio da Equação 5.

$$
I P_{i}=\sum_{j=1}^{n} P Q_{i j} \times I Q_{j}^{*}
$$

Após a definição da importância de cada um dos componentes, propõe-se a correção do resultado considerando a dificuldade de implementação $\left(F_{i}\right)$ e a importância do componente para o produto final $\left(F D_{i}\right)$, conforme a escala apresentada na Tabela 6.

A partir desses índices, calculou-se a importância corrigida de cada um dos componentes de acordo com a Equação 6.

$$
I P_{i}^{*}=I P_{i} \times \sqrt{F_{i}} \times \sqrt{F D_{i}}
$$

Para o preenchimento correto da matriz dos componentes, apresentada na Tabela 7 , a equipe de projeto respondeu à seguinte pergunta: "quanto este 
componente do produto $(i)$ influencia a obtenção deste requisito do produto $(j)$ ?'

Da mesma forma que na matriz da qualidade, os índices resultantes $I P_{i}^{*}$ foram reunidos em um gráfico, representado na Figura 3.

0 gráfico (Figura 3) mostra a priorização dos componentes em relação à sua importância para o produto final. A partir dessa análise, é possível determinar quais componentes poderão ser retirados da fórmula sem comprometer a qualidade demandada pelo cliente. Observa-se que o tensoativo é o componente que mais influencia a obtenção dos requisitos do detergente, ou seja, o tensoativo é o componente decisivo para atender aos requisitos dos clientes. Os demais componentes, embora comumente empregados na fabricação de produtos de limpeza, apresentam uma relação mais fraca para com os requisitos demandados pelos clientes para um detergente. 0 gráfico (Figura 3) demonstra, claramente, a diferença de importância entre os componentes, sendo que os de menor impacto são, a princípio, os componentes que poderão ser excluídos.

Tabela 6. Escalas de avaliação dos parâmetros $F_{i}$ e $F D_{i}$.

\begin{tabular}{cc}
\hline Dificuldade de & \multicolumn{1}{l}{ Importância do } \\
implantação $\left(F_{i}\right):$ & componente $\left(F D_{i}\right):$ \\
\hline 0,5 - Muito grande & 0,5 - Dispensável \\
1,0 - Grande & 1,0 - Pouco importante \\
1,5 - Moderada & 1,5 - Importante \\
2,0 - Pequena & 2,0 - Fundamental \\
\hline
\end{tabular}

Os componentes eliminados nesta etapa foram: antimicrobiano, corante, essência e agente tampão. Neste caso específico, a redução do número de componentes da fórmula em $20 \%$ foi uma orientação para reduzir o impacto ambiental do detergente. Embora a finalidade desta etapa tenha sido motivada por motivos ambientais, esta matriz também pode ser empregada para a diminuição de partes/materiais com vistas à redução de custos de fabricação. No entanto, a eliminação dos componentes nesta etapa do desenvolvimento de produto não deve ser considerada definitiva, mas uma orientação de projeto. lsso se deve ao fato de que, dependendo das matériasprimas selecionadas e do processo produtivo (a ser definido nas etapas posteriores do QFD), a equipe de projeto deve decidir se é possível suprimir, de fato, todos aqueles componentes. Embora a redução de partes seja uma das diretrizes do ecodesign, como já apresentado no referencial teórico, os componentes/ partes estão relacionados com funções específicas do produto, que precisam estar contempladas pelo produto final. Assim, a eliminação de componentes depende também de encontrar, dentre os componentes/ partes restantes, soluções de projeto que atendam às funções daquelas partes suprimidas.

A avaliação da importância dos componentes demonstra ser eficiente para a identificação daqueles componentes que poderiam ser suprimidos do produto final com o menor impacto nos requisitos dos clientes. Além disso, a redução de componentes nesta etapa do

Tabela 7. Matriz dos componentes (parcial).

\begin{tabular}{|c|c|c|c|c|c|c|c|c|c|c|c|c|c|}
\hline & & & & EQUISI & OS DO I & TERGEN & & & & & & & \\
\hline & & 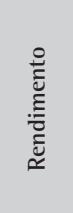 & 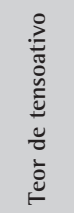 & 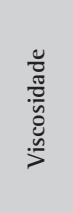 & 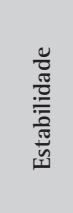 & 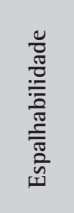 & 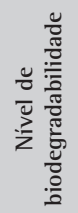 & $\Im$ & 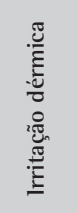 & & & & \\
\hline & $1 Q_{j}^{*}$ & 27,88 & 52,96 & 12,72 & 16,13 & 13,32 & 22,38 & & 17,05 & $I P_{i}$ & $F_{i}$ & $F D_{i}$ & $I P_{i}^{*}$ \\
\hline & Tensoativo ou surfactante & 9 & 9 & & 3 & & 9 & & 9 & 19,83 & 1,0 & 2,0 & 28,04 \\
\hline & Espumante & 3 & 1 & 9 & 3 & 9 & & & & 4,69 & 1,5 & 0,5 & 4,06 \\
\hline$\rightleftarrows$ & Sobre-engordurante & & & & 3 & & 3 & & 9 & 5,91 & 1,5 & 1,0 & 7,23 \\
\hline$\sum_{10}$ & Umectante & & & & 3 & & 3 & & 9 & 4,91 & 1,5 & 1,0 & 6,01 \\
\hline$\frac{Q}{y}$ & Hidrótopo & & 3 & & 9 & & 1 & & & 8,00 & 1,0 & 0,5 & 5,66 \\
\hline 侊 & Espessante & & 1 & & 3 & & 9 & & & 4,32 & 2,0 & 1,5 & 7,49 \\
\hline 8 & Corante & & & & & & 1 & & 1 & 1,91 & 2,0 & 0,5 & 1,91 \\
\hline 品 & Essência & & & & & & 1 & & 1 & 2,10 & 2,0 & 0,5 & 2,10 \\
\hline$\sum_{i=}^{E}$ & Agente Tampão & & & & & & 1 & & 1 & 2,51 & 0,5 & 1,5 & 2,17 \\
\hline z & Antioxidante & & & 9 & & & & & & 2,06 & 1,5 & 1,5 & 3,09 \\
\hline$\sum_{n}^{\bar{c}}$ & Sequestrante & & & & & & 9 & & 1 & 2,06 & 2,0 & 1,5 & 3,56 \\
\hline & Regulador de $\mathrm{pH}$ & & & & 3 & & 3 & & 3 & 2,67 & 2,0 & 1,5 & 4,62 \\
\hline & Antimicrobiano & & & & & & 3 & & 3 & 1,59 & 1,0 & 1,0 & 1,59 \\
\hline & Eliminador de proteínas & & & & & & 1 & & 1 & 4,22 & 0,5 & 1,0 & 2,99 \\
\hline & Veículo & & & & & & 1 & & 1 & 1,53 & 2,0 & 2,0 & 3,05 \\
\hline
\end{tabular}




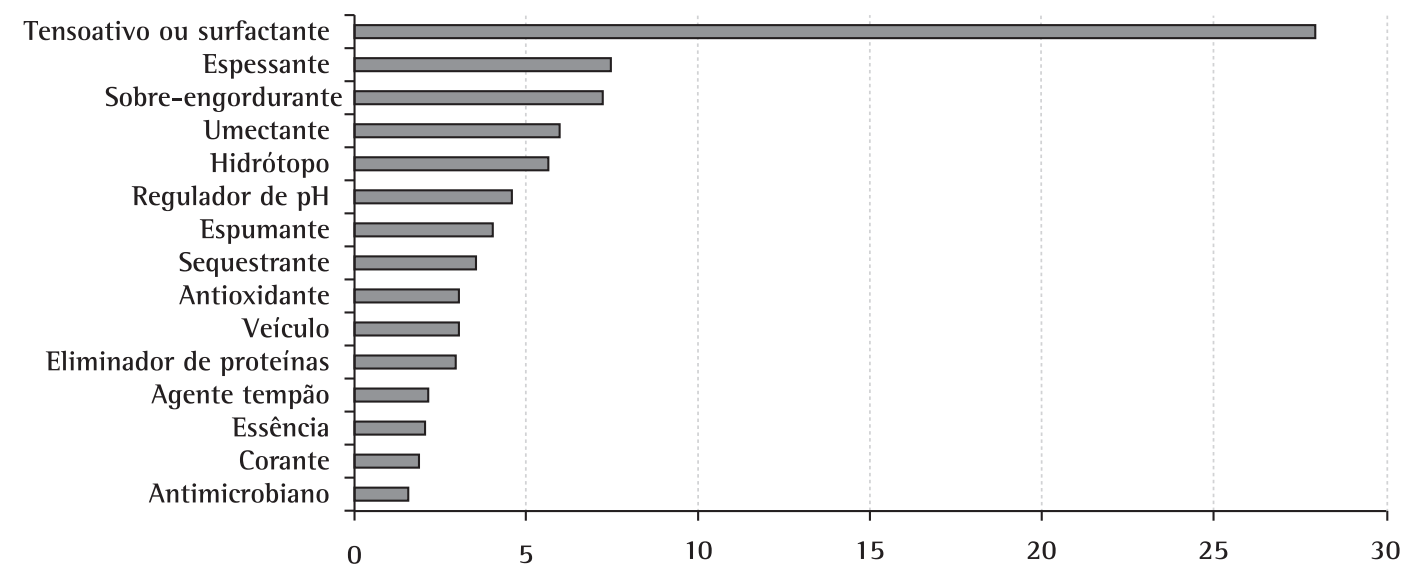

Figura 3. Gráfico com a priorização dos componentes para o detergente.

QFD implica na diminuição da lista de matérias-primas a serem avaliadas na Matriz do Índice $S$, facilitando o processo de definição das matérias-primas. Esse mecanismo é particularmente útil no desenvolvimento de produtos que apresentam muitas partes/componentes e muitas opções de matérias-primas, como é o caso dos produtos químicos e farmacêuticos.

\subsection{Avaliação da sustentabilidade das matérias-primas}

Nesta etapa, as matérias-primas correspondentes aos componentes que não foram eliminados na etapa anterior deveriam ser levantadas por meio de consultas às bases de dados do fabricante, catálogos de fabricantes e fornecedores, entre outros. Esse levantamento seria utilizado como entrada para a Matriz de geração do Índice $S$, descrita em detalhes por Marx e Paula (2008). Para efeitos deste trabalho, no entanto, foram utilizados os resultados obtidos em um estudo prévio de aplicação da Matriz do Índice $S$, realizado junto a uma micro-empresa parceira do projeto (MARX; PAULA, 2008). Nessa ocasião, diversas matérias-primas disponíveis para a fabricação de detergentes foram avaliadas, obtendo-se seus respectivos Índices $S$.

Assim, nesta etapa, as matérias-primas foram organizadas por componente dentro da Matriz do Índice $S$ já existente, e os índices de sustentabilidade ponderados pela importância relativa de cada componente $\left(I P_{i}^{*}\right)$. Como resultado, obteve-se o Índice $S^{*}$, que permite priorizar as matérias-primas, tanto em relação a seu grau de sustentabilidade quanto à importância da função desempenhada no produto final.

A Tabela 8 apresenta a Matriz do Índice $S$, com as matérias-primas organizadas por componente e seus respectivos Índices $S$, obtidos de acordo com a métrica descrita no referencial teórico (MARX; PAULA, 2008). A Tabela 8 apresenta, ainda, nas colunas à direita, o resultado final da ponderação do índice $S$ pela importância relativa de cada componente $\left(I P_{i}^{*}\right)$, calculado de acordo com a Equação 7.

$$
\text { Índice } S^{*}=\text { Índice } S \times I P_{i}^{*}
$$

Após a ponderação realizada na matriz, as matérias-primas foram organizadas por componente e em ordem decrescente do Índice $S^{*}$ em uma lista, parcialmente representada na Tabela 9.

Observe que algumas matérias-primas apresentaram Índices $S^{*}$ muito baixos, significando que são pouco sustentáveis de acordo com os critérios de avaliação usados na matriz. Por esse motivo, essas matériasprimas deverão ser evitadas durante a seleção das alternativas e definição do conceito do novo detergente. No entanto, como já foi argumentado por Marx e Paula (2008), mesmo que as matérias-primas tenham apresentado baixos índices de sustentabilidade, elas não devem ser descartadas como alternativas de solução, uma vez que restrições técnicas de processo ou a incompatibilidade entre matérias-primas podem inviabilizar o uso de alternativas mais sustentáveis.

Neste estudo, foram utilizados os resultados previamente obtidos em uma aplicação anterior e isolada da Matriz do Índice $S$. De fato, Marx e Paula (2008) alegam que os Índices $S$ obtidos pela matriz poderiam ser empregados de diversas maneiras, especialmente na forma de lista e como alternativa a uma base de dados. A manutenção de uma lista desse tipo agiliza a aplicação da matriz, uma vez que, no caso do projeto de um novo produto, bastaria multiplicar o Índice $S$ pelo valor de $I P_{i}^{*}$ obtido na avaliação dos componentes/partes do novo produto. A título de ilustração, a Matriz do Índice $S$ foi apresentada na 
Tabela 8. Matriz do Índice S, com as matérias-primas ponderadas em relação à importância relativa dos componentes.

Peso $\left(W_{j}\right)$
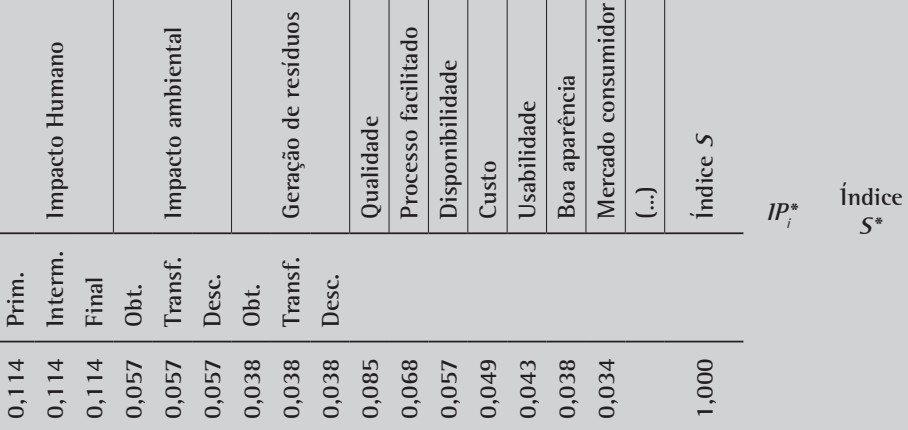

\begin{tabular}{lllllllllllllllllllll} 
Estearato de trietanolamina & 1 & 3 & 9 & 1 & 1 & 3 & 1 & 3 & 3 & 9 & 9 & 9 & 9 & 9 & 9 & 9 & 5,395 & 28,04 & 151,29 \\
\hline
\end{tabular}

\begin{tabular}{lllllllllllllllllllll} 
Oleato de trietanolamina & 1 & 3 & 9 & 1 & 1 & 3 & 1 & 3 & 3 & 3 & 9 & 9 & 9 & 9 & 9 & 9 & 4,885 & 28,04 & 136,98 \\
\hline
\end{tabular}

\begin{tabular}{lllllllllllllllllllll}
\hline Ácidos biliares e seus sais & 9 & 9 & 9 & 3 & 3 & 9 & 9 & 9 & 9 & 1 & 1 & 1 & 1 & 1 & 1 & 1 & 5,324 & 28,04 & 149,30 \\
\hline
\end{tabular}

\begin{tabular}{lllllllllllllllllllll}
\hline Alquilsulfatos & 1 & 3 & 9 & 1 & 3 & 3 & 1 & 3 & 3 & 9 & 9 & 9 & 9 & 9 & 9 & 9 & 5,509 & 28,04 & 154,48 \\
\hline
\end{tabular}

\begin{tabular}{lllllllllllllllllllll} 
Alquiléter sulfatos & 1 & 1 & 3 & 1 & 3 & 3 & 1 & 3 & 3 & 9 & 9 & 9 & 9 & 9 & 9 & 9 & 4,599 & 28,04 & 128,98 \\
\hline
\end{tabular}

\begin{tabular}{lllllllllllllllllllll} 
Alquilsulfonatos & 1 & 3 & 9 & 1 & 3 & 3 & 1 & 3 & 3 & 9 & 9 & 9 & 9 & 9 & 9 & 9 & 5,509 & 28,04 & 154,48 \\
\hline
\end{tabular}

\begin{tabular}{llllllllllllllllllllll} 
Tensoativo & Mono ou dialquil fosfatos & 3 & 9 & 9 & 1 & 3 & 3 & 1 & 3 & 1 & 3 & 1 & 1 & 9 & 1 & 3 & 1 & 3,988 & 28,04 & 111,84 \\
\cline { 2 - 11 }
\end{tabular}

\begin{tabular}{llllllllllllllllllllll}
\hline Ésteres de ác. graxos e sacarose & 3 & 9 & 9 & 3 & 9 & 9 & 9 & 9 & 9 & 9 & 3 & 3 & 1 & 3 & 9 & 3 & 6,372 & 28,04 & 178,69 \\
\hline
\end{tabular}

\begin{tabular}{lllllllllllllllllllll}
\hline Cloretos de benzalcônio & 1 & 1 & 1 & 1 & 3 & 3 & 1 & 3 & 3 & 9 & 9 & 9 & 9 & 9 & 9 & 9 & 4,372 & 28,04 & 122,61 \\
\hline
\end{tabular}

\begin{tabular}{lllllllllllllllllllll} 
Brometo de cetil-dimetilamônio & 1 & 1 & 1 & 1 & 3 & 3 & 1 & 3 & 3 & 9 & 9 & 9 & 9 & 9 & 9 & 9 & 4,372 & 28,04 & 122,61 \\
\hline
\end{tabular}

\begin{tabular}{llllllllllllllllllllll} 
Lecitinas & 3 & 9 & 9 & 3 & 3 & 9 & 3 & 9 & 9 & 1 & 1 & 9 & 3 & 1 & 1 & 1 & 4,968 & 28,04 & 139,32 \\
\hline
\end{tabular}

\begin{tabular}{lllllllllllllllllllll}
\hline Sabões de sódio & 3 & 9 & 9 & 3 & 3 & 9 & 3 & 9 & 9 & 3 & 9 & 9 & 9 & 3 & 1 & 3 & 6,130 & 28,04 & 171,91 \\
\hline
\end{tabular}

\begin{tabular}{lllllllllllllllllllll}
\hline Sabões de potásssio & 3 & 9 & 3 & 3 & 3 & 9 & 3 & 9 & 9 & 3 & 9 & 9 & 9 & 3 & 1 & 3 & 5,448 & 28,04 & 152,78 \\
\hline
\end{tabular}

\begin{tabular}{lllllllllllllllllllll} 
Cocoamida propil betaina & 3 & 9 & 9 & 3 & 3 & 3 & 1 & 1 & 9 & 9 & 9 & 3 & 3 & 3 & 9 & 9 & 5,790 & 7,49 & 43,34 \\
\hline
\end{tabular}

\begin{tabular}{lllllllllllllllllllll}
\hline Cocoamida DEA & 3 & 9 & 9 & 1 & 3 & 3 & 1 & 1 & 3 & 9 & 9 & 3 & 3 & 3 & 9 & 9 & 5,448 & 7,49 & 40,78 \\
\hline
\end{tabular}

\begin{tabular}{llllllllllllllllllllll} 
Espumante & Cocoamida MEA & 3 & 9 & 9 & 1 & 3 & 3 & 1 & 1 & 3 & 9 & 9 & 3 & 3 & 3 & 9 & 9 & 5,448 & 7,49 & 40,78 \\
\cline { 2 - 10 }
\end{tabular}

\begin{tabular}{lllllllllllllllllllll}
\hline Monoetanolamida Oleica 5E0 & 3 & 9 & 9 & 1 & 3 & 3 & 1 & 1 & 3 & 9 & 9 & 3 & 3 & 3 & 9 & 9 & 5,448 & 7,49 & 40,78 \\
\hline
\end{tabular}

\begin{tabular}{llllllllllllllllllllll} 
Lanolina & 3 & 9 & 9 & 1 & 9 & 9 & 3 & 9 & 3 & 3 & 1 & 9 & 1 & 3 & 1 & 3 & 5,194 & 7,23 & 37,57 \\
\hline
\end{tabular}

\begin{tabular}{lllllllllllllllllllll}
\hline Álcoois graxos superiores & 3 & 9 & 9 & 3 & 9 & 9 & 3 & 9 & 9 & 9 & 3 & 9 & 3 & 3 & 3 & 3 & 6,356 & 7,23 & 45,97
\end{tabular}

\begin{tabular}{llllllllllllllllllllllll} 
Sobre- & Esteróis & 3 & 9 & 9 & 3 & 9 & 9 & 3 & 9 & 9 & 1 & 1 & 1 & 1 & 1 & 1 & 1 & 4,756 & 7,23 & 34,40 \\
\cline { 2 - 10 }
\end{tabular}

\begin{tabular}{lllllllllllllllllllllll} 
engordurante & Ésteres ác. graxos e polióis & 3 & 9 & 9 & 3 & 9 & 9 & 3 & 9 & 3 & 9 & 9 & 9 & 3 & 1 & 9 & 3 & 6,678 & 7,23 & 48,30 \\
\cline { 2 - 12 }
\end{tabular}

\begin{tabular}{lllllllllllllllllllll}
\hline Ésteres ác. graxos polioxietilenados & 1 & 3 & 9 & 1 & 3 & 3 & 1 & 9 & 3 & 9 & 9 & 9 & 1 & 3 & 9 & 3 & 4,883 & 7,23 & 35,32 \\
\hline
\end{tabular}

\begin{tabular}{lllllllllllllllllllll} 
Glicerina & 3 & 9 & 9 & 9 & 9 & 9 & 9 & 9 & 9 & 9 & 9 & 9 & 9 & 9 & 9 & 9 & 8,318 & 6,01 & 49,98 \\
\hline
\end{tabular}

\begin{tabular}{lllllllllllllllllllll} 
Umectante & Propilenoglicol & 3 & 9 & 9 & 1 & 1 & 1 & 1 & 3 & 1 & 9 & 9 & 9 & 9 & 9 & 9 & 9 & 6,114 & 6,01 & 36,73 \\
\cline { 2 - 8 }
\end{tabular}

\begin{tabular}{lllllllllllllllllllll}
\hline Extratos vegetais & 9 & 9 & 9 & 3 & 9 & 9 & 9 & 9 & 9 & 3 & 3 & 1 & 3 & 3 & 3 & 3 & 6,300 & 6,01 & 37,85 \\
\hline
\end{tabular}

$\begin{array}{lllllllllllllllllllll}\text { Uréia } & 1 & 3 & 3 & 3 & 3 & 9 & 1 & 9 & 3 & 9 & 3 & 9 & 9 & 3 & 3 & 3 & 4,413 & 5,66 & 24,96\end{array}$

\begin{tabular}{lllllllllllllllllllll}
\hline Óleo de mamona etoxilado & 1 & 3 & 9 & 3 & 3 & 9 & 3 & 9 & 3 & 9 & 1 & 9 & 3 & 3 & 9 & 1 & 4,901 & 5,66 & 27,72 \\
\hline
\end{tabular}

Hidrótopo

\begin{tabular}{lllllllllllllllllllll}
\hline Tolueno sulfonato de sódio & 1 & 1 & 3 & 1 & 3 & 1 & 1 & 3 & 1 & 9 & 1 & 3 & 9 & 1 & 3 & 3 & 2,747 & 5,66 & 15,54 \\
\hline
\end{tabular}

\begin{tabular}{llllllllllllllllllll}
\hline Xileno sulfonato de sódio & 1 & 1 & 3 & 1 & 3 & 1 & 1 & 3 & 1 & 9 & 1 & 3 & 9 & 1 & 3 & 3 & 2,747 & 5,66 & 15,54
\end{tabular}

$\begin{array}{lllllllllllllllllllll}\text { Amido e amido modificado } & 9 & 9 & 9 & 3 & 9 & 9 & 9 & 9 & 9 & 9 & 9 & 9 & 9 & 9 & 9 & 9 & 8,658 & 4,62 & 40,02\end{array}$

\begin{tabular}{lllllllllllllllllllll}
\hline Carboximetilcelulose & 3 & 9 & 9 & 3 & 9 & 9 & 1 & 9 & 9 & 9 & 9 & 9 & 3 & 9 & 9 & 9 & 7,378 & 4,62 & 34,11 \\
\hline
\end{tabular}

\begin{tabular}{llllllllllllllllllllll}
\multirow{2}{*}{ Espessante } & Cloreto de sódio & 1 & 9 & 9 & 1 & 9 & 9 & 3 & 9 & 9 & 9 & 9 & 9 & 9 & 9 & 9 & 9 & 7,407 & 4,62 & 34,24 \\
\cline { 2 - 5 } & 3 & 9 & 9 & 3 & 3 & 9 & 3 & 9 & 9 & 9 & 1 & 1 & 1 & 9 & 9 & 9 & 6,014 & 4,62 & 27,80
\end{tabular}

\begin{tabular}{lllllllllllllllllllll} 
Hidroxietilcelulose & 1 & 9 & 9 & 3 & 9 & 9 & 1 & 9 & 3 & 9 & 9 & 9 & 3 & 9 & 9 & 9 & 6,923 & 4,62 & 32,00 \\
\hline
\end{tabular}

\begin{tabular}{lllllllllllllllllllll}
\hline Polímeros sintéticos & 1 & 9 & 9 & 1 & 3 & 1 & 1 & 3 & 1 & 9 & 9 & 9 & 9 & 9 & 9 & 9 & 6,001 & 4,62 & 27,74 \\
\hline
\end{tabular}

$\begin{array}{lllllllllllllllllllll}\text { Corantes naturais } & 9 & 9 & 9 & 1 & 9 & 9 & 3 & 3 & 9 & 3 & 9 & 3 & 3 & 9 & 9 & 9 & 6,942 & 4,06 & 28,20\end{array}$


Tabela 8. Continuação...

\begin{tabular}{|c|c|c|c|c|c|c|c|c|c|c|c|c|c|c|c|c|c|c|c|c|}
\hline & \multirow[t]{3}{*}{ Peso $\left(W_{j}\right)$} & & 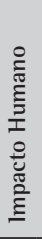 & & & 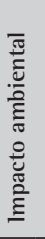 & & & 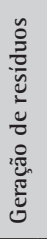 & & 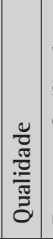 & 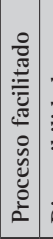 & 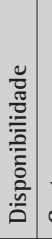 & $\frac{2}{3}$ & 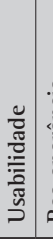 & 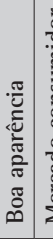 & 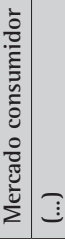 & 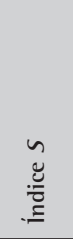 & \multirow[t]{3}{*}{$I P_{i}^{*}$} & \multirow[t]{3}{*}{$\begin{array}{l}\text { Índice } \\
S^{*}\end{array}$} \\
\hline & & $\dot{\underline{\xi}}$ & 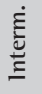 & $\underset{\text { 跴 }}{ }$ & ठें & 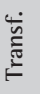 & & ث̊ & 岕 & ڤ̆ & & & & & & & & & & \\
\hline & & $\frac{ \pm}{0}$ & $\frac{ \pm}{ \pm}$ & $\frac{ \pm}{\overline{0}}$ & $\begin{array}{l}\hat{2} \\
0 \\
0\end{array}$ & $\begin{array}{l}\hat{\text { กิ }} \\
0 \\
0\end{array}$ & $\begin{array}{l}\hat{\text { ñ }} \\
0 \\
0\end{array}$ & $\begin{array}{l}\infty \\
\tilde{O} \\
0 \\
0\end{array}$ & $\begin{array}{l}\infty \\
\tilde{0} \\
0 \\
0\end{array}$ & $\begin{array}{l}\stackrel{\infty}{\tilde{O}} \\
0 \\
0\end{array}$ & $\begin{array}{l}L_{0}^{\infty} \\
0 \\
0 \\
0\end{array}$ & $\begin{array}{l}\infty \\
0 \\
0 \\
0\end{array}$ & $\begin{array}{l}\hat{\text { กิ }} \\
0 \\
0\end{array}$ & $\begin{array}{l}\text { g } \\
\\
0\end{array}$ & fै & $\begin{array}{c}\infty \\
\tilde{0} \\
0 \\
0\end{array}$ & 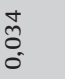 & $\stackrel{8}{\circ}$ & & \\
\hline \multirow{2}{*}{ Sequestrante } & EDTA & 1 & 9 & 9 & 1 & 9 & 3 & 1 & 3 & 3 & 9 & 9 & 9 & 9 & 9 & 9 & 9 & 6,533 & 2,99 & 19,51 \\
\hline & EHDP & 1 & 3 & 3 & 1 & 9 & 3 & 1 & 9 & 3 & 9 & 9 & 3 & 3 & 3 & 95 & 9 & 4,503 & 2,99 & 13,45 \\
\hline \multirow{5}{*}{$\begin{array}{l}\text { Regulador } \\
\text { de } \mathrm{pH}\end{array}$} & Ácido cítrico & 1 & 9 & 9 & 1 & 9 & 9 & 1 & 9 & 9 & 9 & 9 & 9 & 3 & 9 & 95 & 9 & 7,037 & 2,17 & 15,27 \\
\hline & Ácido clorídrico & 1 & 1 & 9 & 1 & 9 & 1 & 1 & 3 & 1 & 3 & 3 & 9 & 9 & 9 & 9 & 9 & 4,515 & 2,17 & 9,80 \\
\hline & Bicarbonato de sódio & 1 & 3 & 9 & 3 & 3 & 9 & 1 & 9 & 9 & 3 & 9 & 9 & 9 & 9 & 95 & 9 & 5,911 & 2,17 & 12,82 \\
\hline & Carbonato de sódio & 3 & 3 & 9 & 3 & 3 & 9 & 1 & 9 & 3 & 3 & 9 & 9 & 9 & 9 & 35 & 9 & 5,682 & 2,17 & 12,33 \\
\hline & Hidróxido de sódio & 1 & 1 & 3 & 1 & 3 & 3 & 1 & 9 & 1 & 9 & 3 & 9 & 3 & 9 & 95 & 9 & 4,049 & 2,17 & 8,79 \\
\hline \multirow{3}{*}{ Antimicrobiano } & Formaldeído & 1 & 1 & 1 & 1 & 3 & 1 & 1 & 3 & 1 & 9 & 3 & 3 & 9 & 3 & 35 & 9 & 2,946 & 2,10 & 6,17 \\
\hline & Nipagin & 1 & 3 & 3 & 1 & 9 & 1 & 1 & 3 & 1 & 9 & 9 & 9 & 3 & 9 & $9 \mathrm{c}$ & 9 & 4,685 & 2,10 & 9,82 \\
\hline & Nipasol & 1 & 3 & 3 & 1 & 9 & 1 & 1 & 3 & 1 & 9 & 9 & 9 & 3 & 9 & 95 & 9 & 4,685 & 2,10 & 9,82 \\
\hline \multirow{3}{*}{$\begin{array}{l}\text { Eliminador de } \\
\text { proteínas }\end{array}$} & Enzimas & 3 & 3 & 9 & 3 & 3 & 9 & 3 & 9 & 9 & 9 & 3 & 3 & 1 & 9 & 9 & 9 & 5,582 & 1,91 & 10,66 \\
\hline & Suco de frutas & 9 & 9 & 9 & 9 & 9 & 9 & 3 & 9 & 9 & 9 & 3 & 3 & 1 & 3 & 93 & 3 & 7,168 & 1,91 & 13,68 \\
\hline & Extrato de plantas & 3 & 9 & 9 & 3 & 9 & 9 & 3 & 9 & 9 & 9 & 3 & 3 & 3 & 3 & 93 & 3 & 6,242 & 1,91 & 11,92 \\
\hline \multirow{3}{*}{ Veículo } & Água & 9 & 9 & 9 & 3 & 3 & 3 & 9 & 9 & 9 & 9 & 9 & 9 & 9 & 9 & 9 & 9 & 7,974 & 1,59 & 12,65 \\
\hline & Chás & 9 & 9 & 9 & 3 & 3 & 3 & 3 & 9 & 9 & 9 & 9 & 9 & 3 & 9 & 35 & 9 & 7,224 & 1,59 & 11,46 \\
\hline & Solventes & 1 & 1 & 3 & 1 & 1 & 1 & 1 & 3 & 1 & 9 & 1 & 3 & 1 & 3 & 9 & 9 & 2,759 & 1,59 & 4,38 \\
\hline
\end{tabular}

Tabela 9. Lista de matérias-primas priorizadas em função do Índice $S^{*}$ para os componentes 'tensoativo', 'regulador de pH' e 'espessante'.

\begin{tabular}{lc}
\hline \multicolumn{1}{c}{ Tensoativo } & Índice $S^{*}$ \\
\hline Ésteres de ácidos graxos e sacarose & 178,69 \\
Sabões de sódio & 171,91 \\
Alquilsulfonatos & 154,48 \\
Alquilsulfatos & 154,48 \\
Sabões de potásssio & 152,78 \\
Estearato de trietanolamina & 151,29 \\
Ácidos biliares e seus sais & 149,30 \\
Lecitinas & 139,32 \\
Oleato de trietanolamina & 136,98 \\
Alquiléter sulfatos & 128,98 \\
Cloretos de benzalcônio & 122,61 \\
Brometo de cetil-dimetilamônio & 122,61 \\
Mono ou dialquil fosfatos & 111,84 \\
\hline \multicolumn{1}{c}{ Regulador de pH } & Índice $S^{*}$ \\
\hline Ácido cítrico & 15,27 \\
Bicarbonato de sódio & 12,82 \\
Carbonato de sódio & 12,33 \\
Ácido clorídrico & 9,80 \\
Hidróxido de sódio & 8,79 \\
\hline & índice $S^{*}$ \\
\hline Amido e amido modificado & 40,02 \\
Cloreto de sódio & 34,24 \\
Carboximetilcelulose & 34,11 \\
Golimeroxietilcelulose & 32,00 \\
\hline & 27,80 \\
\hline & 27,74 \\
\hline
\end{tabular}

integra, acrescida de duas colunas à direita para a inclusão do valor de $I P_{i}^{*}$ e do resultado final.

Por fim, observou-se que não há diferenças entre 0 Índice $S$ e o Índice $S^{*}$ (ponderado pela funcionalidade), ao analisar as matérias-primas dentro de cada um dos grupos de componentes. No entanto, a ponderação do Indice $S$ pela importância relativa do componente é justificada ao considerar as possíveis configurações do produto final, resultado de inúmeras combinações possiveis entre os componentes e as suas respectivas soluções de projeto - neste caso, as matérias-primas. Dessa forma, espera-se que o Índice $S^{*}$ das matériasprimas seja um facilitador para a realização de tradeoffs durante a construção da matriz morfológica e definição do conceito final do detergente.

Apesar de não estarem detalhadas neste artigo, o estudo também contemplou as demais etapas do modelo descritivo da Figura 1. Após o preenchimento da Matriz do Índice $S$, os dados da matriz da qualidade foram resgatados para o preenchimento da matriz de processos, que relaciona os requisitos do produto aos processos produtivos necessários para a sua fabricação. É importante observar a sequência de preenchimento das matrizes, pois tanto a eliminação de alguns componentes quanto a seleção e combinação de matérias-primas específicas realizadas nas etapas anteriores tiveram impacto nos processos 
de fabricação do produto avaliados nas matrizes e, consequentemente, nos recursos e custos envolvidos.

No caso estudado, a eliminação de alguns componentes teve impacto sobre os processos avaliados, em função das soluções de projeto selecionadas para o novo detergente. Isso foi confirmado pela aplicação das últimas matrizes, de processos, recursos humanos e de infraestrutura. Os resultados evidenciaram a importância dos processos de mistura e embalagem, das atividades de engenharia de processo e inspeção e dos equipamentos de mistura e rotulagem. A melhoria dos processos tradicionais e o eventual investimento na contratação de pessoal e aquisição de equipamentos são algumas das ações consideradas necessárias para a garantia da qualidade do novo detergente sustentável.

\section{Conclusões}

Este trabalho apresenta uma proposta para auxiliar o desenvolvimento de novos produtos sustentáveis, a partir das demandas de um mercado-alvo, considerando também as dimensões ambientais, sociais e econômicas da sustentabilidade. 0 uso da ferramenta QFD contribuiu para o projeto de um novo detergente biodegradável orientado pelos requisitos dos clientes e alinhado a critérios de sustentabilidade, por meio da incorporação da Matriz do Índice $S$ e de uma avaliação da importância dos componentes do produto.

0 trabalho demonstra a adaptabilidade da ferramenta QFD como direcionador para os objetivos que se deseja alcançar, no caso, a sustentabilidade. Assim, este trabalho amplia a aplicação do QFD, contribuindo para discussões a respeito da elaboração de um QFD para a sustentabilidade. Os resultados obtidos com a incorporação da Matriz do Índice $S$ ao QFD indicam ser possível adaptar a fabricação de produtos químicos, como é o caso dos detergentes, a critérios de sustentabilidade de forma simplificada, garantindo a qualidade do produto. Embora a definição do conceito do detergente não esteja descrita neste trabalho, os resultados obtidos no estudo de caso contribuíram efetivamente para o projeto do detergente.

Como discutido previamente, a avaliação da sustentabilidade de matérias-primas pela Matriz do Índice $S$ não precisa ser realizada combinada ao QFD. No entanto, a utilização em conjunto com o QFD, permitiu ponderar os Índices $S$ obtidos para cada matéria-prima em função de sua importância para o detergente, importância esta definida na matriz dos componentes. Além disso, a matriz mostrou-se adequada para integração ao QFD, uma vez que seu preenchimento segue a mesma lógica e escala.

Embora a avaliação das matérias-primas na Matriz do Índice $S$ seja uma tarefa especializada, o estudo demonstra que os esforços para avaliar as matériasprimas por meio dessa matriz podem compensar. A avaliação prévia das matérias-primas e a utilização dos resultados pré-existentes (Índices $S$ ) simplificaram o trabalho e facilitaram a obtenção do índice de sustentabilidade ponderado pela importância dos componentes do detergente. No entanto, é preciso destacar que o método apresentado mostrou-se adequado apenas para aplicações industriais, uma vez que a avaliação ambiental baseia-se na experiência da equipe e não em análises químicas.

Assim, como sugestões para trabalhos futuros estão o aperfeiçoamento do método, a descrição das demais etapas do QFD indicadas no modelo descritivo e a aplicação da proposta no desenvolvimento de produtos de outra natureza, como bens duráveis ou produtos de manufatura.

\section{Referências}

ABELE, E.; ANDERL, R.; BIRKHOFER, H. G. Environmentallyfriendly product development: methods and tools. Londres: Springer, 2005. 318 p. http://dx.doi. org $/ 10.1007 / \mathrm{b} 138604$

BAUMANN, H.; BOONS, F.; BRAGD, A. Mapping the green product development field: engineering, policy and business perspectives. Journal of Cleaner Production, v. 10 , n. 5, p. 409-425, 2002. http://dx.doi.org/10.1016/ S0959-6526(02)00015-X

BEVILACQUA, M.; CIARAPICA, F. E.; GIACCHETTA, G. A fuzzyQFD approach to supplier selection. Journal of Purchasing \& Supply Management, v. 12, n. 1, p. 14-27, 2006. http://dx.doi.org/10.1016/j.pursup.2006.02.001

BHAMRA, T. A. et al. Integrating environmental decisions into the product development process: part 1 the early stages. In: INTERNATIONAL SYMPOSIUM ON ENVIRONMENTALLY CONSCIOUS DESIGN AND INVERSE MANUFACTURING, 1., 1999, Tokyo. Proceedings... Tokyo: EcoDeNet, 1999. p. 757-762.

BOSCH, V. G.; ENRÍQUEZ, F. T. TQM and QFD: exploiting a customer complaint management system. International Journal of Quality \& Reliability Management, v. 22, n. 1, p. 30-37, 2005. http://dx.doi. org/10.1108/02656710510572977

BOTTANI, E.; RIZZI; A. Strategic management of logistics service: A fuzzy QFD approach. International Journal of Production Economics, v. 103, n. 2, p. 585-599, 2006. http://dx.doi.org/10.1016/j.ijpe.2005.11.006

BREZET, H.; HEMEL, C. Ecodesign: a promising approach to sustainable production and consumption. Paris: UNEP, 1997.

CHAKRABORTY, S.; DEY, S. QFD-based expert system for nontraditional machining processes selection. Expert Systems with Applications, v. 32, n. 4, p. 1208-1217, 2007. http:// dx.doi.org/10.1016/j.eswa.2006.02.010

CHEN, Y.; FUNG, R. Y. K.; TANG, J. Rating technical attributes in fuzzy QFD by integrating fuzzy weighted average method and fuzzy expected value operator. European Journal of Operational Research, v. 174, n. 3, p. 1553-1566, 2006. http://dx.doi.org/10.1016/j. ejor.2004.12.026 
CHEN, L. H.; WENG, M. C. An evaluation approach to engineering design in QFD processes using fuzzy goal programming models. European Journal of Operational Research, n. 172, n. 1, p. 230-248, 2006.

CHENG, L. C.; MELO FILHO, L. D. R. QFD: desdobramento da função qualidade na gestão de desenvolvimento de produtos. São Paulo: Editora Blücher, 2007.

CLAUSING, D. Total quality development: a step-by-step guide to world-class concurrent engineering. New York: ASME, 1994.

DIEHL, J. C.; BREZET, H. Design for sustainability: an approach for international development, transference and local implementation. In: International Conference Environmental Management for Sustainable Universities, 2004, Monterrey. Proceedings... Monterrey, p. $s / n$.

DIKMEN, 1.; BIRGONUL, M. T.; KIZILTAS, S. Strategic use of quality function deployment (QFD) in the construction industry. Building and Environment, v. 40, n. 2, p. 245-255, 2005. http://dx.doi.org/10.1016/j. buildenv.2004.07.001

EDGEMAN, R. L.; HENSLER, D. A. QFD and the BEST paradigm: deploying sustainable solutions. World Review of Science, Technology and Sustainable Development, v. 2, n. 1, p. 49-59, 2005. http://dx.doi.org/10.1504/ WRSTSD.2005.006727

FABRI, J. A.; CARVALHO, M. M. QFD estendido em ambiente de gerenciamento de informações para ensino distância. Produção Online, v. 5, n. 2, p. s/n, 2005.

FERREIRA, M. G. G. et al. A review of strategies for knowledge management in early stages os the product development process. Management \& Development, v. 4, n. 5, p. 105113, 2006.

FIKSEL, J. Design for environment: an integrated systems approach. In: INTERNATIONAL SYMPOSIUM ON ELECTRONICS AND ENVIRONMENT, 1993, Arlington. Proceedings... Arlington, 1993. p. 126-131. http:// dx.doi.org/10.1109/ISEE.1993.302823

GlL, A. C. Como elaborar projetos de pesquisa. São Paulo: Atlas, 2007. $175 \mathrm{p}$.

GOLDANI, L. et al. Escolha de matérias-primas com base no ecodesign e desenvolvimento sustentável: matriz de tomada de decisão. In: Salão de Iniciação Científica, 19; Feira de Iniciação Científica, 16., 2007, Porto Alegre. Livro de Resumos. Porto Alegre: UFRGS, 2007. p. 241241.

HALOG, A; SCHULTMANN, F; RENTZ, O. Using quality function deployment for technique selection for optimum environmental performance improvement. Journal of Cleaner Production, v. 9, n. 5, p. 387-394, 2001. http:// dx.doi.org/10.1016/S0959-6526(00)00080-9

HANUMAIAH, N.; RAVl, B.; MUKHERJEE, N. P. Rapid hard tooling process selection using QFD-AHP methodology. Journal of Manufacturing Technology Management, v. 17, n. 3, p. 332-350, 2006. http://dx.doi. org/10.1108/17410380610648290

HEEJEONG, Y.; HERRMANN, C. Eco-voice of consumer (VOC) on QFD. In: International Symposium on Environmentally Conscious Design and Inverse Manufacturing, 3., 2003, Tokyo. Proceedings... Tokyo: EcoDeNet, p. 618-625.

JOHANSSON, G. Success factors for integration of ecodesign in product development: a review of state of the art. Environmental Management and
Health, v. 13, n. 1, p. 98-107, 2002. http://dx.doi. org/10.1108/09566160210417868

KAHRAMAN, C.; ERTAY, T.; BÜYÜKÖZKAN, G. A fuzzy optimization model for QFD planning process using analytic network approach. European Journal of Operational Research, v. 171, n. 2, p. 390-411, 2006. http://dx.doi.org/10.1016/j.ejor.2004.09.016

KARA, S., HONKE, I., KAEBERNICK, H. An integrated framework for implementing sustainable product development. In: INTERNATIONAL SYMPOSIUM ON ENVIRONMENTALLY CONSCIOUS DESIGN AND INVERSE MANUFACTURING, 4., 2005, Tokyo. Proceedings... Tokyo: EcoDeNet, 2005. p. 684-691.

KILLEN, C. P.; WALKER, M.; HUNT, R. A. Strategic planning using QFD. International Journal of Quality \& Reliability Management, v. 22, n. 1, p. 17-29, 2005. http://dx.doi. org/10.1108/02656710510572968

KOBAYASHI, Y. et al. A practical method for quantifying eco-efficiency using ecodesign support tools. Journal of Industrial Ecology, v. 9, n. 4, p. 131-144, 2005. http:// dx.doi.org/10.1162/108819805775247990

KWONG, C. K. et al. Methodology of determining aggregated importance of engineering characteristics in QFD. Computers \& Industrial Engineering, n. 53, p. 667679, 2007. http://dx.doi.org/10.1016/j.cie.2007.06.008

LABUSCHAGNE, A. C.; BRENT, A. C.; ERCK, R. P. G. Assessing the sustainability performances of industries. Journal of Cleaner Production, v. 13, n. 4, p. 373-385, 2005. http:// dx.doi.org/10.1016/j.jclepro.2003.10.007

LAl, X.; TAN, K. C.; XIE, M. Optimizing product design using quantitative quality function deployment: a case study. Quality and Reliability Engineering International, v. 23, n. 1, p. 45-57, 2007. http://dx.doi.org/10.1002/qre.819

LEPREVOST, J.;MAZUR, G. Qualityinfrastructure improvement: using QFD to manage project priorities and project management resources. International Journal of Quality \& Reliability Management, v. 22, n. 1, p. 10-16, 2005. http://dx.doi.org/10.1108/02656710510572959

MANZINI, E.; VEZZOLI, C. O desenvolvimento de produtos sustentáveis: os requisitos ambientais dos produtos industriais. São Paulo: Editora da Universidade de São Paulo, 2005. 366 p.

MARSOT, J. QFD: a methodological tool for integration of ergonomics at the design stage. Applied Ergonomics, v. 36, n. 2, p. 185-192, 2005. http://dx.doi.org/10.1016/j. apergo.2004.10.005

MARX, A. M. Proposta de método de gestão de requisitos para o desenvolvimento de produtos sustentáveis. 2009. 140 f. Dissertação (Mestrado em Engenharia de Produção)Universidade Federal do Rio Grande do Sul, Porto Alegre, 2009.

MARX, A. M.; PAULA, I. C. Índice de sustentabilidade para matérias-primas e formulações químicas. GEPROS, ano 3, n. 4, p. 29-44, 2008.

MASUI, K.; SAKAO, T.; INABA, A. Quality function deployment for environment: QFDE (1st report)-a methodology in early stage of DfE. In: International Symposium on Environmentally Conscious Design and Inverse Manufacturing, 2., Tokyo, 2001. Proceedings... Tokyo: EcoDeNet, p. 567-574.

MELO FILHO, L. D. R.; CHENG, L. C. QFD na garantia da qualidade do produto durante seu desenvolvimento caso em uma empresa de materiais. Produção, v. 17, n. 3 , 
p. 604-624, 2007. http://dx.doi.org/10.1590/S010365132007000300015

MIGUEL, P. A. C. QFD no desenvolvimento de novos produtos: um estudo sobre a sua introdução em uma empresa adotando a pesquisa-ação como abordagem metodológica. Produção, v. 19, n. 1, p. 105-128, 2009. http://dx.doi.org/10.1590/S0103-65132009000100008

MIZUNO, S.; AKAO, Y. QFD: the costumer-driven approach to quality planning and development. Tokyo: Asian Productivity Association, 1994. 365 p.

MORAES, C. C.; MIGUEL, P. A. C. Proposta de melhoria de um curso de mestrado em engenharia de produção por meio do uso do QFD - contexto de uma avaliação institucional. GEPROS, ano 2, v. 4, p. 23-36, 2007.

PAHL, G. et al. Projeto na engenharia: fundamentos do desenvolvimento eficaz de produtos, métodos e aplicações. São Paulo: Edgar Blücher, 2005.

PRAMOD, v. r. et al. Integrating TPM and QFD for improving quality in maintenance engineering. Journal of Quality in Maintenance Engineering, v. 12, n. 2, p. 150-171, 2006. http://dx.doi.org/10.1108/13552510610667174

PUJARI, D.; WRIGHT, G. Integrating environmental issues into product development: understanding the dimensions of perceived driving forces. Journal of Euro Marketing, v. 7, n. 4, p. 43-63, 1999. http://dx.doi.org/10.1300/ J037v07n04_03

RIBEIRO, J. L. D. et al. Material-operations matrix: a tool for marketing research and sustainable product development. In: International Symposium on Business and Industrial Statistics, 2007, Azores. Program and Abstracts. Azores, p. 138-139.
RIBEIRO, J. L. D.; ECHEVESTE, M. E.; DANILEVICZ, A. M. D. A utilização do QFD na otimização de produtos, processos e serviços: produtos, processos, serviços. Porto Alegre: FEEng; UFRGS, 2001. $98 \mathrm{p}$.

ROZENFELD, $\mathrm{H}$. et al. Gestão de desenvolvimento de produtos: uma referência para a melhoria do processo. São Paulo: Saraiva, 2006

SAKAO, T.; WATANABE, K.; SHIMOMURA, Y. A method to support environmentally conscious service design using Quality Function Deployment (QFD). In: International Symposium on Environmentally Conscious Design and Inverse Manufacturing, 3., 2003, Tokyo. Proceedings... Tokyo: EcoDeNet, p. 567-574.

STRASSER, C.; WIMMER, W. Supporting customer driven eco-solutions - implementing ecodesign in the daily work of product developers. In: International Symposium on Environmentally Conscious Design and Inverse Manufacturing, 3., 2003, Tokyo. Proceedings... Tokyo: EcoDeNet, p. 757-762.

UGWU, 0. 0.; HAUPT, T. C. Key performance indicators and assessment methods for infrastructure sustainability - a South African construction industry perspective. Building and Environment, v. 42, n. 2, p. 665-680, 2007. http:// dx.doi.org/10.1016/j.buildenv.2005.10.018

\section{Agradecimentos}

Sinceros agradecimentos ao CNPq, pelo apoio financeiro ao projeto de pesquisa.

\title{
Quality function deployment applied to a sustainable detergent project
}

\begin{abstract}
This paper aims to introduce a modified QFD model that incorporates sustainability criteria, as well as its application in a sustainable detergent case. The inclusion of these criteria takes place through an evaluation of the detergent components relative importance, which allows the reduction of product parts and the incorporation of a matrix for raw materials sustainability assessment. The model application allowed the prioritization of the detergent components, indicating which of them could be eliminated with minimal impact on the product demands. After that, the available raw materials were evaluated according to the sustainability criteria and were prioritized according to their relative importance to the final product. The results of this study indicated that the model proposed is adequate to industrial application, contributing to the development of more sustainable products, still driven by market demands.
\end{abstract}

\section{Keywords}

QFD. Project. Product. Sustainability. 
Marx, A. M. et al.

Desdobramento da função qualidade ... detergente sustentável. Produção, v. 21, n. 4, p. 724-741, out./dez. 2011

Apêndice 1. Questionário quantitativo aplicado no estudo.

\begin{tabular}{|c|c|c|c|c|c|c|c|c|c|c|}
\hline \multicolumn{11}{|l|}{ Favor não preencher este quadro } \\
\hline Data: & \multicolumn{3}{|c|}{ Entrevistador: } & & & & & & & \\
\hline \multicolumn{11}{|c|}{$\begin{array}{l}\text { Para desenvolver um detergente inovador e de qualidade precisamos de sua opinião para definir o que é necessário neste produto. Responda } \\
\text { este questionário com atenção e sinceridade. Obrigado pela colaboração. }\end{array}$} \\
\hline \multicolumn{11}{|c|}{ Nas questões de 1 a 6 gostaríamos que você expressasse sua opinião quanto a importância dos itens listados. } \\
\hline 1. Rendimento & \multicolumn{2}{|c|}{$\begin{array}{c}\text { SEM } \\
\text { IMPORTÂNCIA }\end{array}$} & \multicolumn{2}{|c|}{\begin{tabular}{|c|} 
POUCO \\
IMPORTANTE
\end{tabular}} & \multicolumn{2}{|c|}{ INDIFERENTE } & \multicolumn{2}{|c|}{ IMPORTANTE } & \multicolumn{2}{|c|}{$\begin{array}{c}\text { MUITO } \\
\text { IMPORTANTE }\end{array}$} \\
\hline Facilidade de espalhar & 1 & 2 & 3 & 4 & 5 & 6 & 7 & 8 & 9 & 10 \\
\hline Durabilidade do produto em condições de uso & 1 & 2 & 3 & 4 & 5 & 6 & 7 & 8 & 9 & 10 \\
\hline Que utiliza pequenas quantidades para realizar a limpeza & 1 & 2 & 3 & 4 & 5 & 6 & 7 & 8 & 9 & 10 \\
\hline 2. Capacidade de limpeza & \multicolumn{2}{|c|}{\begin{tabular}{c|c|c|} 
SEM & \\
IMPORTÂNCIA
\end{tabular}} & \multicolumn{2}{|c|}{\begin{tabular}{c|} 
POUCO \\
IMPORTANTE \\
\end{tabular}} & \multicolumn{2}{|c|}{ INDIFERENTE } & \multicolumn{2}{|c|}{ IMPORTANTE } & \multicolumn{2}{|c|}{$\begin{array}{c}\text { MUITO } \\
\text { IMPORTANTE }\end{array}$} \\
\hline Capacidade desengordurante & 1 & 2 & 3 & 4 & 5 & 6 & 7 & 8 & 9 & 10 \\
\hline Capacidade de remover sujeira & 1 & 2 & 3 & 4 & 5 & 6 & 7 & 8 & 9 & 10 \\
\hline Capacidade de remover cheiro & 1 & 2 & 3 & 4 & 5 & 6 & 7 & 8 & 9 & 10 \\
\hline 3. Produto (características físicas) & \multicolumn{2}{|c|}{$\begin{array}{c}\text { SEM } \\
\text { IMPORTÂNCIA } \\
\end{array}$} & \multicolumn{2}{|c|}{\begin{tabular}{|c|c|} 
POUCO \\
IMPORTANTE \\
\end{tabular}} & \multicolumn{2}{|c|}{ INDIFERENTE } & \multicolumn{2}{|c|}{ IMPORTANTE } & \multicolumn{2}{|c|}{$\begin{array}{c}\text { MUITO } \\
\text { IMPORTANTE }\end{array}$} \\
\hline Cor agradável & 1 & 2 & 3 & 4 & 5 & 6 & 7 & 8 & 9 & 10 \\
\hline Cheiro agradável & 1 & 2 & 3 & 4 & 5 & 6 & 7 & 8 & 9 & 10 \\
\hline Consistência líquida & 1 & 2 & 3 & 4 & 5 & 6 & 7 & 8 & 9 & 10 \\
\hline 4. Produto (características de uso) & \multicolumn{2}{|c|}{$\begin{array}{c}\text { SEM } \\
\text { IMPORTÂNCIA }\end{array}$} & \multicolumn{2}{|c|}{\begin{tabular}{c|} 
POUCO \\
IMPORTANTE
\end{tabular}} & \multicolumn{2}{|c|}{ INDIFERENTE } & \multicolumn{2}{|c|}{ IMPORTANTE } & \multicolumn{2}{|c|}{$\begin{array}{c}\text { MUITO } \\
\text { IMPORTANTE }\end{array}$} \\
\hline Ter pH neutro (ser suave para as mãos) & 1 & 2 & 3 & 4 & 5 & 6 & 7 & 8 & 9 & 10 \\
\hline Dar brilho & 1 & 2 & 3 & 4 & 5 & 6 & 7 & 8 & 9 & 10 \\
\hline Fazer espuma & 1 & 2 & 3 & 4 & 5 & 6 & 7 & 8 & 9 & 10 \\
\hline 5. Características sanitárias & \multicolumn{2}{|c|}{$\begin{array}{c}\text { SEM } \\
\text { IMPORTÂNCIA }\end{array}$} & $\begin{array}{r}\text { POI } \\
\text { IMPOR }\end{array}$ & ANTE & INDI & ENTE & IMPC & ANTE & $\begin{array}{r}\mathrm{M} \\
\mathrm{IMPC}\end{array}$ & $\begin{array}{l}\text { TO } \\
\text { ANTE }\end{array}$ \\
\hline Produto biodegradável & 1 & 2 & 3 & 4 & 5 & 6 & 7 & 8 & 9 & 10 \\
\hline Ser hipoalergênico & 1 & 2 & 3 & 4 & 5 & 6 & 7 & 8 & 9 & 10 \\
\hline Aprovado pela vigilância sanitária & 1 & 2 & 3 & 4 & 5 & 6 & 7 & 8 & 9 & 10 \\
\hline 6. Características de mercado & IMP & ÂA & $\begin{array}{r}\text { POI } \\
\text { IMPOR } \\
\end{array}$ & ANTE & INDI & ENTE & IMPC & ANTE & $\begin{array}{r}\mathrm{M} \\
\mathrm{IMPC}\end{array}$ & $\begin{array}{l}\text { TO } \\
\text { ANTE }\end{array}$ \\
\hline Preço competitivo & 1 & 2 & 3 & 4 & 5 & 6 & 7 & 8 & 9 & 10 \\
\hline Propagandas explicativas & 1 & 2 & 3 & 4 & 5 & 6 & 7 & 8 & 9 & 10 \\
\hline Qualidade (reconhecimento da marca) & 1 & 2 & 3 & 4 & 5 & 6 & 7 & 8 & 9 & 10 \\
\hline 7. Enumere de 1 (mais importante) até 6 (menos importante & e) sem & tir nenl & hum nún & & & & & & & \\
\hline ( ) Ter um bom rendimento & & & & & & & & & & \\
\hline ( ) Limpar bem & & & & & & & & & & \\
\hline ( ) Ter uma aparência atraente & & & & & & & & & & \\
\hline ( ) Ser fácil de usar & & & & & & & & & & \\
\hline ( ) Não prejudicar a natureza & & & & & & & & & & \\
\hline ( ) Ser acessivel & & & & & & & & & & \\
\hline Garantimos o seu sigilo e solicitamos somente que preer & os c & ssc & is abaixo. & & & & & & & \\
\hline ldade: & & & Sexo: & 1 & $\mathrm{M}$ & 1 & $\mathrm{~F}$ & & & \\
\hline
\end{tabular}

